\title{
Superficially Projecting Principal Neurons in Layer V of Medial Entorhinal Cortex in the Rat Receive Excitatory Retrosplenial Input
}

\author{
Rafał Czajkowski, ${ }^{1,2 \star}$ Jørgen Sugar, ${ }^{1 \star}$ Sheng-Jia Zhang, ${ }^{1}$ Jonathan J. Couey, ${ }^{1}$ Jing Ye, ${ }^{1}$ and Menno P. Witter ${ }^{1}$ \\ ${ }^{1}$ Kavli Institute for Systems Neuroscience, Centre for Neural Computation, Faculty of Medicine, Norwegian University of Science and Technology, 7491 \\ Trondheim, Norway, and ${ }^{2}$ Neurobiology Center, Nencki Institute of Experimental Biology, 02-093 Warsaw, Poland
}

Principal cells in layer $\mathrm{V}$ of the medial entorhinal cortex (MEC) have a nodal position in the cortical-hippocampal network. They are the main recipients of hippocampal output and receive inputs from several cortical areas, including a prominent one from the retrosplenial cortex (RSC), likely targeting basal dendrites of layer $\mathrm{V}$ neurons. The latter project to extrahippocampal structures but also relay information to the superficial layers of MEC, closing the hippocampal- entorhinal loop. In the rat, we electrophysiologically and morphologically characterized RSC input into MEC and conclude that RSC provides an excitatory input to layer V pyramidal cells. Ultrastructural analyses of anterogradely labeled RSC projections showed that RSC axons in layer V of MEC form predominantly asymmetrical, likely excitatory, synapses on dendritic spines $(90 \%)$ or shafts $(8 \%)$, with $2 \%$ symmetrical, likely inhibitory, synapses on shafts and spines. The overall excitatory nature of the RSC input was confirmed by an optogenetic approach. Patterned laser stimulation of channelrhodopsin-expressing presynaptic RSC axons evoked exclusively EPSPs in recorded postsynaptic layer V cells. All responding layer $\mathrm{V}$ pyramidal cells had an axon extending toward the white matter. Half of these neurons also sent an axon to superficial layers. Confocal imaging of RSC synapses onto MEC layer V neurons shown to project superficially by way of retrogradely labeling from superficial layers confirmed that proximal dendrites of superficially projecting cells are among the targets of inputs from RSC. The excitatory RSC input thus interacts with both entorhinal-cortical and entorhinal-hippocampal circuits.

\section{Introduction}

The entorhinal cortex (EC) is anatomically positioned as a gateway to the hippocampal formation (HF), gathering and preprocessing information from other brain areas and providing the main cortical input to HF (Eichenbaum and Lipton, 2008). HF plays a central role in spatial information processing (O'Keefe and Nadel, 1978), and it contains place cells that fire when an animal is in a certain location (O'Keefe and Dostrovsky, 1971). Layers II and III of the medial entorhinal cortex (MEC) harbor a number of spatially modulated cell types (Hafting et al., 2005;

Received June 21, 2013; revised Aug. 6, 2013; accepted Aug. 23, 2013.

Author contributions: R.C., J.S., and M.P.W. designed research; R.C., J.S., and J.J.C. performed research; S.-J.Z. and J.Y. contributed unpublished reagents/analytic tools; R.C., J.S., and J.J.C. analyzed data; R.C., J.S., and M.P.W. wrote the paper.

This work was supported by the Kavli Foundation, Norwegian Research Council Centre of Excellence Grant 145993, Equipment Grant 181676, and Research Grant 191929, and European Commission ("Spacebrain") Grant 200873. We thank Ragnhild Gisetstad for technical assistance with the design of the electron microscopy experiments and Paulo Girão for help with data analysis. The use of the electron microscopy facility at Norwegian University of Science and Technology and the help and advice of Nan Skogaker, Linh Hoang, and Gro Møkkelgjerd is greatly acknowledged.

${ }^{*}$ R.C. and J.S. contributed equally to this study.

The authors declare no competing financial interests.

Correspondence should be addressed to Menno Witter, Kavli Institute for Systems Neuroscience and Centre for Neural Computation, Norwegian University of Science and Technology, Medical Technical Research Centre, Postboks 8905, N0-7491 Trondheim, Norway. E-mail: menno.witter@ntnu.no.

J. J. Couey's present address: Department of Psychiatry, Erasmus Medical Center, 3015 CE Rotterdam, The Netherlands.

DOI:10.1523/JNEUROSCI.2646-13.2013

Copyright $\odot 2013$ the authors $\quad 0270-6474 / 13 / 3315779-14 \$ 15.00 / 0$
Sargolini et al., 2006; Solstad et al., 2008), contributing a necessary spatial input to hippocampal place cells (Remondes and Schuman, 2004; Brun et al., 2008; Moser and Moser, 2008; Van Cauter et al., 2008; van Strien et al., 2009; Ito and Schuman, 2012; Zhang et al., 2013).

Hippocampally processed information targets dendrites of neurons in EC layer V (van Haeften et al., 1995), and many MEC layer $\mathrm{V}$ pyramidal cells send axon collaterals to cortical targets (Insausti et al., 1997). In view of this connectivity, MEC layer V neurons are thought to play an important role in the interaction between the HF and cortex (Chrobak and Buzsáki, 1994; Buzsáki, 1996; Kloosterman et al., 2000, 2003a). MEC layer V neurons also project locally to superficial layers of EC (Kloosterman et al., 2003b; van Haeften et al., 2003), strengthening their nodal position in the network.

The basal dendrites of layer $\mathrm{V}$ neurons are not only innervated by inputs from HF but are also embedded in a prominent input from the retrosplenial cortex (RSC; Jones and Witter, 2007). RSC is involved in a variety of behaviors related to spatial navigation. In humans, lesions of RSC cause a deficit in which patients cannot use familiar landmarks or maps to produce a sense of direction (Maguire, 2001). The RSC shows increased activity during route planning (Spiers and Maguire, 2006; Epstein et al., 2007). In rodents, RSC contains head direction cells (Cho and Sharp, 2001), and lesion studies demonstrated an involvement in tasks that depend on spatial memory (Vann and Aggleton, 2002; Pothuizen et al., 2008; Wesierska et al., 2009). 
Interactions between RSC and the HF-EC circuit have been postulated as crucial for spatial memory formation (Vann et al., 2009). The absence of direct projections from RSC to HF point to layer $\mathrm{V}$ neurons in MEC as the likely substrate to mediate the interactions between RSC and HF. However, details about the synaptic organization of the RSC projections to MEC are unknown, and most importantly it is currently not known whether RSC-targeted cells in layer V actually project to superficial layers II and III of MEC. Our aim was to characterize the RSC to layer $\mathrm{V}$ projection at the synaptic level, asking first whether it is excitatory or inhibitory and second whether its postsynaptic target cells include superficially projecting pyramidal neurons in layer $\mathrm{V}$. To this end, we combined neuroanatomical and optogenetic in vitro electrophysiological experiments.

\section{Materials and Methods \\ Surgery}

Thirty adult female Sprague Dawley rats (Charles River) of 197-257 g weight were used in this study. The rats were housed in individual cages under a controlled environment $\left(21 \pm 1^{\circ} \mathrm{C}\right.$; humidity, $60 \%$; lights on from $8: 00$ P.M. to 8:00 A.M.). Food and water were available ad libitum. The experimental protocols followed the European Communities Council Directive and the Norwegian Experiments on Animals Act and were approved by the Animal Welfare Committee of the Norwegian University of Science and Technology. Surgeries for tracer and recombinant adeno-associated virus (rAAV) injections were performed as described previously, with minor modifications (Kononenko and Witter, 2012). Animals were anesthetized with isoflurane and mounted in a stereotaxic frame (David Kopf Instruments). For each injection, openings were made in the skull exposing the brain surface over RSC or MEC. The stereotactic coordinates were based on the topographical description of RSC-toMEC projections (Jones and Witter, 2007) and a stereotaxic rat brain atlas (Paxinos and Watson, 2007). Nomenclature is according to Sugar et al. (2011). The anteroposterior coordinates were measured from the posterior transverse sinus, $2.5 \mathrm{~mm}$ laterally to the midsagittal sinus, and the dorsoventral coordinates were measured from the brain surface after removal of the dura.

Three different experimental methods were used (Fig. 1). First we injected rAAV (titer $10^{-12}$ ) into caudal RSC area 29b (A29b) and A29c in 11 rats. Each animal received a total volume of $3 \mu \mathrm{l}$, with $1 \mu \mathrm{l}$ being injected in each of three different dorsoventral positions using a $10 \mu \mathrm{l}$ NanoFil syringe assembled on a UMP3 pump (WPI). Each injection took $10 \mathrm{~min}$, and we waited for 15 additional minutes before retracting the syringe. Second, the anterograde tracer biotinylated dextran amine [5\% BDA, 10,000 molecular weight (Invitrogen) in $0.1 \mathrm{M} \mathrm{PBS}$ ] was iontophoretically injected (positive-pulsed current of $6 \mu \mathrm{A}, 6 \mathrm{~s}$ on, $6 \mathrm{~s}$ off for $10 \mathrm{~min}$ ) into caudal RSC, in 19 rats using a glass micropipette with an inner tip diameter of presubiculum.
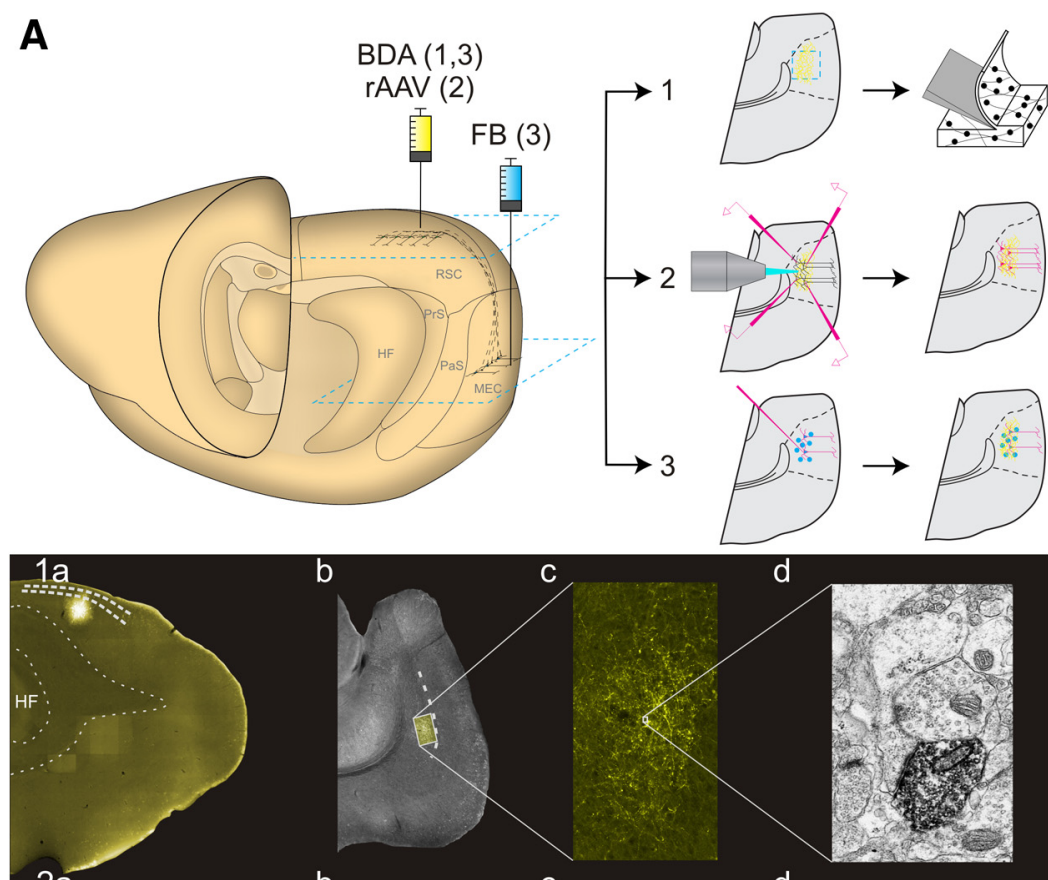

C
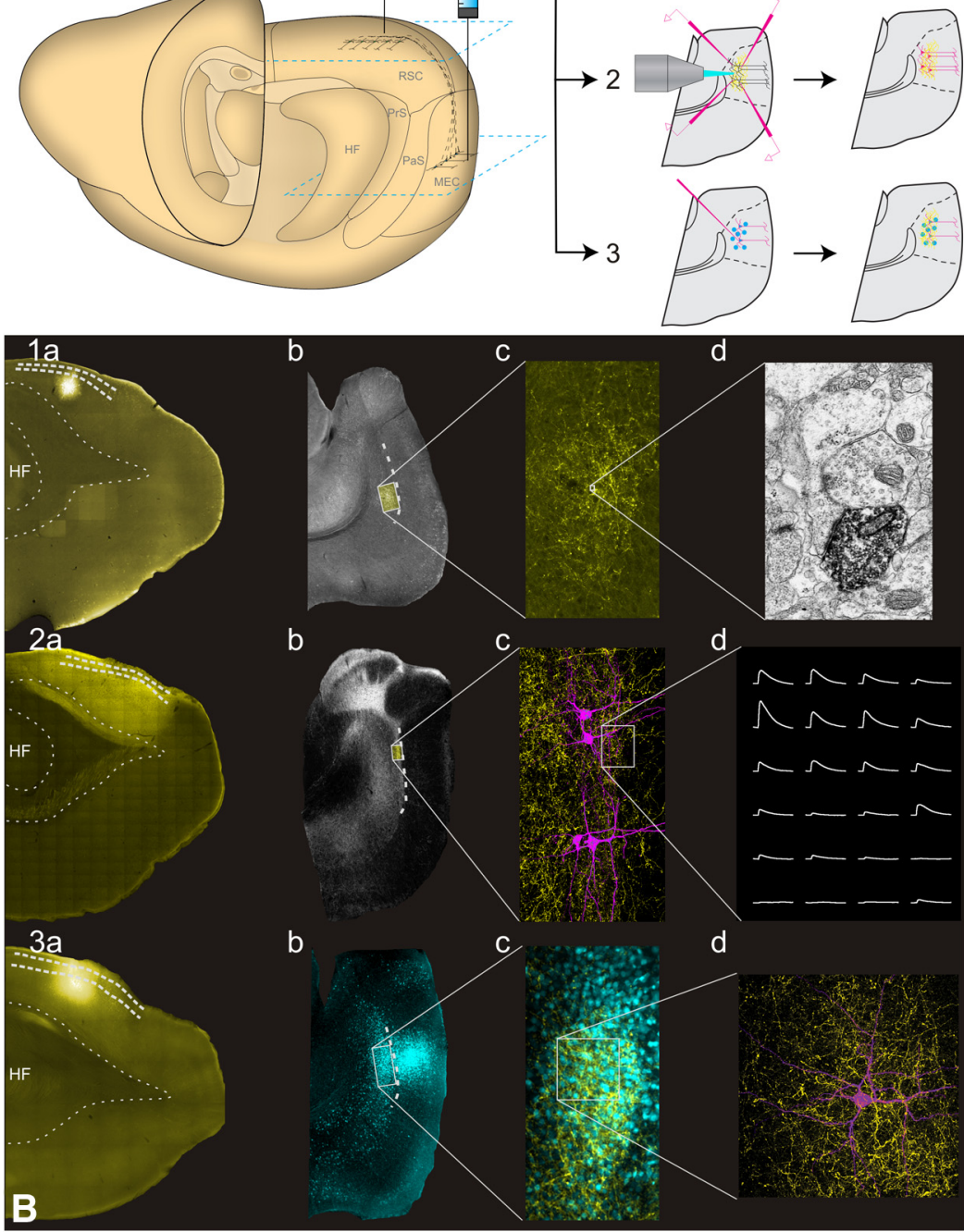

d

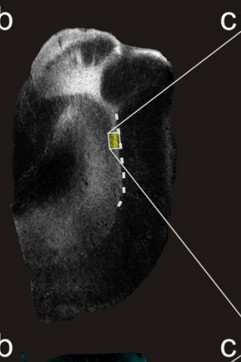

C.
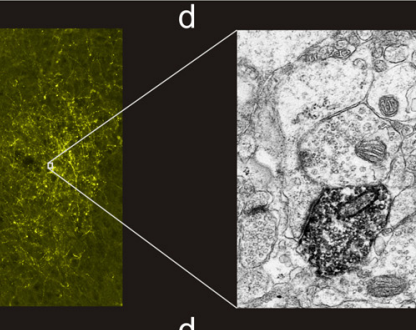

d
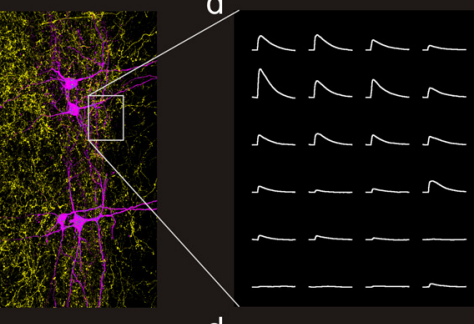

,

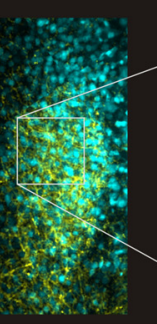

d

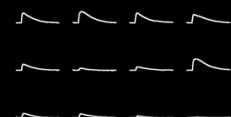

igure 1. Experimental approaches used in the experiments. $A$, Schematic drawing of the rat brain and the injection sites (left). 1, The anterograde tracer BDA was injected into RSC for EM experiments. 2, rAAV was injected in RSC for optogenetic experiments. 3, The retrograde tracer FB was injected into superficial layers of MEC and BDA was injected into RSC for confocal experiments. The blue squares depict the level of the horizontal sections of the MEC and RSC shown in $\boldsymbol{B}$. Each of the three experimental setups resulted in an anterogradely labeled plexus in MEC (yellow), intracellularly filled cells in Experiments 2 and 3 (magenta), and in Experiment 3 also retrogradely labeled neurons in MEC (blue dots). $\boldsymbol{B}$, Examples of individual experimental protocols. 1, For EM experiments, BDA was labeled with AF546-conjugated streptavidin so that injections ( $\mathbf{1 a})$ and an anterograde plexus $(\mathbf{1 b}, \mathbf{1} \boldsymbol{c})$ could be identified (yellow). Sections were processed for EM, and synaptic complexes labeled with DAB were sampled in EM (1d). 2, For in vitro optogenetic experiments, mCherry fluorescence (yellow) was used for identifying the injection in $\operatorname{RSC}(\mathbf{2} \boldsymbol{a})$, anterograde plexus in $\operatorname{MEC}(\mathbf{2} \boldsymbol{b}, \mathbf{2 c})$, where intracellular recordings and axonal reconstructions were performed $(\mathbf{2 c}, \mathbf{2 d})$. 3, For confocal analysis, BDA was labeled with AF488 (yellow; 3a, 3c), and FB-positive cells (blue; 3b, 3c) were filled with AF568 (magenta; 3d). PaS, Parasubiculum; PrS,

9-15 $\mu \mathrm{m}$. Multiple injections involving different anteroposterior or dorsoventral levels were made aiming to involve at least parts of A29b, A29c, or A30. Third, eight of the rats also received injections with the retrograde tracer fast blue (FB; EMS-Chemie, $1 \%$ solution in PBS) in superficial layers of MEC. A volume of $150 \mathrm{nl}$ was delivered with a $1 \mu \mathrm{l}$ Hamilton syringe over $5 \mathrm{~min}$, and the dye was allowed to diffuse for 15 min before removal of the syringe. Before the end of surgeries, the animals were given a dose of buprenorphine (Temgesic, $0.05 \mathrm{mg} / \mathrm{kg}$; RB Pharmaceuticals) or carprofen (Rimadyl, $5 \mathrm{mg} / \mathrm{kg}$; Pfizer) 
subcutaneously. Suturing the skin over the wound completed surgery, and the animal was allowed to recover.

\section{Optogenetic experiments}

Viral vector construct and packaging. AAV2/2 was prepared and packaged with the Stratagene AAV Helper-Free System according to the user manual of the manufacturer. The purification, titration, and verification were described previously (Couey et al., 2013; Zhang et al., 2013). It was used to express the optogenetic effector in retrosplenial neurons projecting to MEC layer V. We used a light-gated cation channel ChIEF, a chimera of channelrhodopsin 1 (ChR1) and ChR2 from the unicellular green alga Chlamydomonas reinhardtii (ChIEF was provided as a generous gift by Dr. John Y. Lin from the laboratory of Dr. Roger Y. Tsien at the University of California, San Diego, San Diego, CA). It preserves the high ion permeability of ChR2 while gaining the reduced inactivation of ChR1. An additional point mutation, I170V, improves the channel closure rate after stimulation (Lin et al., 2009). The proviral vector containing ChIEF fused with mCherry under control of the calcium/calmodulin-dependent protein kinase II $\alpha$ ( $\alpha$ CaMKII) promoter was prepared as described previously (Couey et al., 2013). Before use, all virus batches were titer matched by diluting to $1 \times 10^{12}$ viral genomic particles/ml in PBS.

In vitro recordings. After a survival time of up to 6 weeks after injections of rAAV, animals were anesthetized with isoflurane and perfused through the heart with a small volume of ice-cold artificial CSF (ACSF) cutting solution containing the following (in $\mathrm{mM}$ ): 110 choline chloride, $25 \mathrm{NaHCO}_{3}, 25$ D-glucose, 11.6 sodium ascorbate, $7 \mathrm{MgSO}_{4}, 3.1$ sodium pyruvate, $2.5 \mathrm{KCl}, 1.25 \mathrm{NaH}_{2} \mathrm{PO}_{4}$, and $0.5 \mathrm{CaCl}_{2}$ (aerated with $95 \%$ $\mathrm{O}_{2} / 5 \% \mathrm{CO}_{2}$ before decapitation). The brain was quickly dissected, and $400-\mu \mathrm{m}$-thick horizontal slices of the RSC or MEC were cut with a vibratome (model 3000; Harvard Apparatus) and incubated in oxygenated ACSF containing the following (in $\mathrm{mm}$ ): $127 \mathrm{NaCl}, 25 \mathrm{NaHCO}_{3}, 25$ D-glucose, $2.5 \mathrm{KCl}, 2 \mathrm{MgSO}_{4}, 1 \mathrm{CaCl}_{2}$, and $1.25 \mathrm{NaH}_{2} \mathrm{PO}_{4}$ (for $45 \mathrm{~min}$ at $37^{\circ} \mathrm{C}$ ). Thereafter, the slices were oxygenated at room temperature until used.

Multiple whole-cell recordings were made with glass micropipettes filled with a standard intracellular solution containing the following (in mM): $120 \mathrm{~K}$-gluconate, $10 \mathrm{KCl}, 10 \mathrm{HEPES}, 10 \mathrm{~K}$-phosphocreatine, 4 ATP-Mg, and 0.4 GTP, pH adjusted to 7.3 with $\mathrm{KOH}$ (270-285 mOsm). Biocytin (3-5 mg/ml; Sigma) was included in the pipette for later anatomical verification of cell location and morphology. All recordings were done at $34^{\circ} \mathrm{C}$ in ACSF with $1.5 \mathrm{~mm} \mathrm{MgSO}_{4}$ and $2 \mathrm{~mm} \mathrm{CaCl}_{2}$. Layer $\mathrm{V}$ cells in MEC or RSC were first visualized using infrared differential interference contrast (IR-DIC) microscopy. Individual cells or groups of cells $\sim 100 \mu \mathrm{m}$ deep from the cutting surface were visually identified, and up to four neighboring cells were targeted for whole-cell patch. All cells were first maintained in the "on cell" configuration until all contacts had achieved a $+1 \mathrm{G} \Omega$ resistance. The entire cluster was then opened to whole-cell configuration. Recordings were made in current-clamp mode with the membrane potential maintained between -60 and $-65 \mathrm{mV}$. After the whole-cell configuration was established, recorded responses to steps of current injection allowed to electrophysiologically classify each cell (Canto and Witter, 2012). Recordings were made using Axon Multiclamp amplifiers (Molecular Devices) sampling at intervals of $100 \mu \mathrm{s}$ $(10 \mathrm{kHz})$, digitized using an ITC-1600 analog-to-digital interface in combination with custom acquisition software based on Igor Pro version 6.0 (WaveMetrics). The same software was also used to control whole-cell current injection (both timing and levels). Series resistance was compensated to a maximum bridge balance value of $20 \mathrm{M} \Omega$. In case series resistance exceeded this value, recordings were not included in signal analysis.

For photostimulation, we used a customized laser control system (UGA-40 with a $473 \mathrm{~nm}$ laser; Rapp OptoElectric) coupled to a microscope (Olympus BX51WI) equipped with a water-immersion objective [40×, 0.8 numerical aperture (NA); Olympus] and controlled by the recording software. This configuration resulted in a beam diameter of $\sim 5$ $\mu \mathrm{m}$ and power adjustable up to $650 \mu \mathrm{W}$ at the specimen (scattering in the tissue was not taken into account). Stimuli were arranged in a rectangular $8 \times 6$ grid with $20 \mu \mathrm{m}$ spacing, positioned over the recorded cluster avoiding interference from the recording pipettes. The stimulus duration was $2 \mathrm{~ms}$, delivered to each point of the grid in a pseudorandom order with $250 \mathrm{~ms}$ interval. The stimulation pattern was repeated 30 times. Voltage deflections were cut at a threshold of 10 SDs beyond the average variation of the membrane potential before being identified as a response. The voltage responses obtained from stimulation of each unique location in the grid were averaged to produce a normalized mean response for each point. Voltage deflections that did not reach the threshold were not included in the average. Only grid locations with eight or more identified responses were included in subsequent analysis. From the averaged responses, onset times and amplitudes were determined for each location. In several slices, we blocked action potentials (APs) by adding tetrodotoxin (TTX; $5 \mu \mathrm{M}$; Sigma), a neurotoxin that binds to voltage-gated $\mathrm{Na}^{+}$channels (Narahashi et al., 1964). The drug was diluted in ACSF and perfused into the chamber after control recordings. After 1 min incubation, stimulation was repeated 30 times. Data analysis was done offline using Igor and MATLAB (WaveMetrics) software.

Immunohistochemistry. Immediately after each recording session, the slices were placed in $4 \%$ paraformaldehyde (PFA) overnight and subsequently permeabilized by washing seven times with $0.1 \mathrm{M}$ phosphate buffer (PB) containing $1 \%$ Triton X-100 (PBT-1\%), blocked for $3 \mathrm{~h}$ with PBT-1\% with 5\% normal goat serum (NGS; X0907; Dako), and then incubated for $72 \mathrm{~h}$ with a monoclonal anti-mCherry antibody (1:500 in PBT- $1 \%$ and $5 \%$ NGS; Clontech) in $4^{\circ} \mathrm{C}$. Slices were then washed three times in $\mathrm{PB}$ and incubated for $12 \mathrm{~h}$ with the mixture of Alexa Fluor (AF) 568 -conjugated anti-mouse secondary antibody (1:350; Invitrogen) and AF488-conjugated streptavidin (1:350; Invitrogen) in PBT-1\% and 5\% NGS in $4^{\circ} \mathrm{C}$. After washing in $\mathrm{PB}$, the sections were incubated with the NeuroTrace deep red fluorescent Nissl stain (1:200; Invitrogen) for 30 min. After staining, the slices were washed in $\mathrm{PB}$, dehydrated in increasing ethanol concentrations (30, 50, 70, 90, and twice in 100\%, $10 \mathrm{~min}$ each) and then in a 1:1 mixture of ethanol/methylsalicylate, and finally cleared and mounted in methylsalicylate.

\section{Electron microscopy}

After 9-14 d of survival, rats with BDA injections in caudal A29b, A29c, and A30 received an overdose of Equithesin $(11 \mathrm{mg} / \mathrm{kg}$ bodyweight, i.p.; Sanofi Sante). They were subsequently transcardially perfused with a fresh filtrated Ringer's solution (in mM: $145 \mathrm{~mm} \mathrm{NaCl}, 3 \mathrm{~mm} \mathrm{KCl}$, and 2 mu $\mathrm{NaHCO}_{3}$ at $4^{\circ} \mathrm{C}$, brought to $\mathrm{pH} 6.9$ with $\mathrm{O}_{2}$ ). Next, the perfusion fluid was changed to $4 \%$ freshly filtered depolymerized PFA (Merck) with $0.1 \%$ glutaraldehyde (Merck) in $125 \mathrm{~mm} \mathrm{~PB}$ at $4^{\circ} \mathrm{C}$. After completion of the perfusion, the brains were removed from the skull and postfixed overnight at $4^{\circ} \mathrm{C}$ in the same fixative. Brains were washed in $125 \mathrm{~mm}$ $\mathrm{PB}$ and cut horizontally with a vibrating microtome (Leica VT1000S; bath fluid, $125 \mathrm{~mm} \mathrm{~PB}, 4^{\circ} \mathrm{C}$ ) at $50 \mu \mathrm{m}$, and all sections were collected into six equally spaced series. The sections were collected in vials containing $\mathrm{PB}$ at $4^{\circ} \mathrm{C}$. The series were then processed in three different ways. One series was transferred to $2 \%$ dimethylsulfoxide (DMSO; Merck) in 125 $\mathrm{mM} \mathrm{PB}$ and $20 \%$ glycerine (Merck) and stored at $-20^{\circ} \mathrm{C}$ for later use, one series was processed for fluorescent microscopy, and the remaining series were processed for electron microscopy (EM).

Processing for fluorescent microscopy. Sections were rinsed three times for $10 \mathrm{~min}$ in $\mathrm{PB}$ and then three times for $10 \mathrm{~min}$ in Tris-buffered saline (TBS; $50 \mathrm{~mm}$ Tris and $153 \mathrm{~mm} \mathrm{NaCl}$ ) with 2\% Triton X-100 (TBS-Tx; Merck), $\mathrm{pH}$ 8.0. The sections were incubated in AF546-conjugated streptavidin (Invitrogen) in a 1:200 solution with TBS-Tx overnight at $4^{\circ} \mathrm{C}$. Next, the sections were rinsed two times for $5 \mathrm{~min}$ in Tris/ $\mathrm{HCl}(50$ mм Tris), $\mathrm{pH} 7.6$, and subsequently mounted on glass slides from a $0.2 \%$ gelatin solution in Tris/HCl. After overnight drying, they were cleared in toluene and coverslipped with Entellan (Merck). Sections were inspected with dark-field and fluorescent illumination at the appropriate excitation wavelength (Zeiss Axio Imager M2), and digital images of the anterogradely labeled plexus in MEC were obtained.

Processing for EM. The sections were rinsed for $10 \mathrm{~min}$ in an ascending series of 10,15 , and $20 \% \mathrm{DMSO}$ in $\mathrm{PB}$ at $4^{\circ} \mathrm{C}$. The sections were quickly frozen in isopentane cooled by solid carbon dioxide and subsequently recovered and thawed. This freeze and thaw procedure was repeated twice. Sections were subsequently rinsed three times for $10 \mathrm{~min}$ in $\mathrm{PB}$ at $4^{\circ} \mathrm{C}$ and two times for $5 \mathrm{~min}$ in TBS, $\mathrm{pH} 7.6$, at $4^{\circ} \mathrm{C}$. The sections were incubated with avidin-biotin-peroxidase complex (Vectastain $\mathrm{ABC}$ kit 
standard, PK-4000; Vector Laboratories) in TBS for $48 \mathrm{~h}$ at $4^{\circ} \mathrm{C}$. Next, they were rinsed for three times for $10 \mathrm{~min}$ in TBS and two times for 5 min in Tris $/ \mathrm{HCl}, \mathrm{pH} 7.6$, and subsequently stained with filtrated diaminobenzidine tetrahydrochloride (DAB; $0.067 \%$ in Tris/HCl; SigmaAldrich) $4^{\circ} \mathrm{C}$, to which a $30 \%$ solution of $\mathrm{H}_{2} \mathrm{O}_{2}$ had been added immediately before use. If during microscopic inspection the projection from the RSC appeared to be clearly labeled in MEC, the DAB reaction was stopped with Tris/ $\mathrm{HCl}$, and the sections were rinsed two times for 5 $\mathrm{min}$ in the same buffer. Brain sections containing the densest anterograde labeling in MEC were selected and further processed.

The EC was carefully dissected from the section and postfixed in the dark for $1 \mathrm{~h}$ in $2 \% \mathrm{OsO}_{4}$ (Merck) in $0.1 \mathrm{M} \mathrm{PB}, \mathrm{pH}$ 7.4. The sections were rinsed two times for $5 \mathrm{~min}$ in $\mathrm{PB}$ and then dehydrated in ascending series of ethanol in water: $50 \%(10 \mathrm{~min}), 70 \%(10 \mathrm{~min}), 90 \%(10 \mathrm{~min})$, and $100 \%$ (four times for $15 \mathrm{~min}$ ). Subsequently, they were put in propylenoxyde (Merck) two times for $15 \mathrm{~min}$, followed by a mixture of propylenoxyde and epoxy resin (Ladd Research), first two volume parts propylenoxyde and one volume part epoxy resin for $30 \mathrm{~min}$, followed by one volume part propylenoxyde and two volume parts epoxy resin for 30 min before they were put in pure epoxy resin overnight. In all solutions including epoxy resin, $1.5 \%$ of dimethylaminomethylphenol was added (Ladd Research). The sections were then embedded in epoxy resin between polyethylene foil (3M Color Laser Transparency film, CG3710) at $60^{\circ} \mathrm{C}$ overnight. All sections were then inspected under a dissection microscope to determine the location of the labeled plexus in MEC. Selected plexus were carefully dissected from the sections and glued with epoxy resin on blocks of procured epoxy resin. The blocks where further cured for $24-48 \mathrm{~h}$ at $60^{\circ} \mathrm{C}$.

After curing, series of ultrathin sections $(60-70 \mathrm{~nm})$ were cut with an ultramicrotome (EM UC6; Leica) equipped with a diamond knife (Diatome ultra $\left.45^{\circ}\right)$ and collected on Formvar-coated $(0.5 \%$ in dichlorethan; Electron Microscopy Sciences), single-slot copper grids. Sections were stained in the dark with $4 \%$ uranyl acetate in $50 \%$ ethanol for 17-20 min and counterstained with 1\% lead citrate (Electron Microscopy Sciences) in $0.1 \mathrm{M} \mathrm{NaOH}$ for $4-5 \mathrm{~min}$. Material was inspected with a transmission electron microscope (JEM-1011; Jeol). Digital images were taken (Morada; Olympus), and lengths of all postsynaptic densities (PSDs) and the shortest and longest diameters of each axonal bouton were measured in iTEM (version 5.0; Olympus Soft Imaging Solutions). Serial images of selected synaptic complexes were imported to Neurolucida (MicroBrightField) to make threedimensional (3D) reconstructions.

Quantitative analysis of synapses. Synapses were obtained from at least two different $50-\mu \mathrm{m}$-thick sections of each of two animals. To increase the likelihood of finding synapses, the densest part of the terminal plexus in a chosen vibratome section was isolated. The synapse type and the postsynaptic target were determined in a randomly selected reference section. All synapses in this ultrathin section were counted, and their phenotype was determined. To be included, a synapse needed to comprise a BDA-labeled axon terminal, an electron-dense synaptic membrane specialization, a morphological identifiable postsynaptic element, and a distinguishable synaptic cleft. To avoid double counting, only synapses that were not visible in a parallel lookup section were used in analyses (Gundersen, 1986). Serial sections were used to establish with certainty the properties of identified synapses.

Synapse properties in terms of presynaptic varicosities and postsynaptic targets were determined on the basis of their overall morphology, using criteria described in detail previously (Gray, 1959; Uchizono, 1965; Colonnier, 1968). Synapses with a thick PSD, round vesicles in the presynaptic element, and a wide synaptic cleft were categorized as asymmetrical synapses, whereas synapses with a thin PSD, pleomorphic vesicles, and a narrow synaptic cleft were classified as symmetrical synapses. Postsynaptic targets were classified as spines if they had a clear cytoplasm and/or a spine apparatus. Postsynaptic targets with mitochondria and/or visible microtubules were classified as dendritic shafts. In each animal, analysis was continued until a sample size of $\sim 100$ synapses was reached.

After categorization of the synapses and postsynaptic targets, all electron micrographs were presented blindly to an unbiased independent observer who was asked to categorize the boutons and postsynaptic target according to the same criteria described above. Boutons and postsynaptic targets on which the first and second observer did not agree were discussed together. For all synapses analyzed the type could be determined.

\section{Confocal analysis of putative synaptic contacts}

Intracellular injections. Twenty-one days after BDA and FB tracer injections, animals were anesthetized by an overdose of Equithesin and perfused transcardially with Ringer's solution, followed by ice cold 4\% PFA in PBS. The brain was extracted and postfixed in $4 \%$ PFA for $2 \mathrm{~h}$ in $4^{\circ} \mathrm{C}$. Next, $100-\mu \mathrm{m}$-thick horizontal slices of RSC were cut using a vibratome (VT1000S; Leica) with ice-cold $0.1 \mathrm{M} \mathrm{PB}$ as bath fluid. Cutting started at the most dorsal level of the brain, and, after reaching the level that comprised the most dorsal part of MEC, alternating 100 and $400 \mu \mathrm{m}$ slices were obtained. The $100-\mu \mathrm{m}$-thick slices were stained for the presence of BDA following the protocol described above for the EM study. The slices were scanned using a slide scanner (MIRAX MIDI; Zeiss) equipped with an AxioCam digital camera (Zeiss). The single filter set \#43 (Zeiss; excitation bandpass, $545 / 25 \mathrm{~nm}$; beam splitter, $570 \mathrm{~nm}$; emission bandpass, $605 / 70 \mathrm{~nm}$ ) was used for RSC sections labeled with AF546. Filter sets \#43 and \#49 (Zeiss; excitation, $365 \mathrm{~nm}$; beam splitter, $395 \mathrm{~nm}$; emission bandpass, 445/50 nm) were used for scanning MEC sections containing AF546 and FB. RSC scans were analyzed to confirm the injection site. MEC scans were used to verify the overlap between RSC fibers (AF546) and retrogradely labeled MEC layer V cells (FB). Adjacent $400 \mu \mathrm{m}$ MEC slices were then placed in a chamber under a fixed-stage upright microscope (Axio Examiner; Zeiss) equipped with PlanApo 20×, 1.0 NA water dipping lenses, micromanipulator (Luigs \& Neumann), and a customassembled iontophoretic injection device. The sections were simultaneously imaged with IR-DIC to resolve cell details and with fluorescent filter set 75HE (Zeiss; excitation, $365 \mathrm{~nm}$; beam splitter, $395 \mathrm{~nm}$; emission bandpass, $445 / 50 \mathrm{~nm}$; separated from the IR-DIC by beam splitter, $660 \mathrm{~nm}$ ) to visualize FB and AF568. Randomly selected FB-positive cells in layer V of MEC were intracellularly injected with a solution of AF568 hydrazide (10 mM in PBS; Invitrogen) using a $70-130 \Omega$ glass pipette. Negative current was applied to the micropipette $(2 \mathrm{nA}, 500 \mathrm{~ms}$ on, 500 ms off) for at least 10 min to completely fill the impaled cell and its dendrites. Immediately after filling, the slices were transferred to $4 \%$ PFA and postfixed overnight in $4^{\circ} \mathrm{C}$. Subsequently, the $400 \mu \mathrm{m}$ slices were permeabilized by washing seven times with PBT-1\%, blocked for $3 \mathrm{~h}$ with PBT-1\% containing 5\% NGS, and then incubated for $24 \mathrm{~h}$ with AF488conjugated streptavidin (1:300 in PBT- $1 \%$ and $5 \%$ NGS) in $4^{\circ} \mathrm{C}$. Slices were then washed three times in $\mathrm{PB}$, dehydrated, mounted in methylsalicylate, and imaged (see below).

Staining for putative synaptic contacts. In case of four intracellularly filled MEC layer V neurons, the existence of putative synaptic contacts with BDA-labeled RSC axons was assessed with the use of confocal laserscanning microscopy. In this material, we stained for the presence of marker molecules for both presynaptic and postsynaptic synaptic elements, i.e., synaptophysin and PSD-95, respectively. After BDA/AF568 confocal imaging (see below), the $400 \mu \mathrm{m}$ slices were rehydrated by reversing the dehydration protocol, washed three times in $\mathrm{PB}$, and incubated in cryoprotective solution ( $30 \% \mathrm{w} / \mathrm{v}$ sucrose in $\mathrm{PB}$ ) overnight. The slices were then flattened and embedded in NEG 50 (Thermo Fisher Scientific) on a cryostat chuck and quickly frozen in $-20^{\circ} \mathrm{C}$. The sections were resliced at $50 \mu \mathrm{m}$ on a Lauda 1720 cryostat (Leitz), washed three times with $0.1 \mathrm{M} \mathrm{PB}$, permeabilized in $0.1 \mathrm{M}$ PB containing $0.5 \%$ Triton X-100 (PBT-0.5\%), blocked for $3 \mathrm{~h}$ with PBT-0.5\% with 5\% NGS, and subsequently incubated for $48 \mathrm{~h}$ with a mixture of a monoclonal antiPSD-95 antibody (1:150, P78352; NeuroMab) and a polyclonal antisynaptophysin antibody (1:100, ab14692; Abcam) in PBT-0.5\% and 5\% NGS in $4^{\circ} \mathrm{C}$. Slices were washed three times in $\mathrm{PB}$ and incubated for $4 \mathrm{~h}$ with the mixture of AF514-conjugated anti-rabbit secondary antibody, AF633-conjugated anti-mouse secondary antibody, and AF488conjugated streptavidin (1:350; all from Invitrogen) in PBT- $0.5 \%$ and $5 \%$ NGS at room temperature. Finally, after three washes in PB, sections were suspended in $0.1 \mathrm{~m}$ Tris- $\mathrm{HCl}$, mounted on Superfrost slides (WPI), dried overnight, and coverslipped in Entellan. 


\section{Confocal microscopy}

All sections were imaged with a Zeiss Meta 510 confocal microscope. Unless indicated otherwise, FB was excited by ultraviolet laser $(\lambda=$ $405 \mathrm{~nm}$; emission bandpass, 450/60 nm), AF488 was excited by argon laser $(\lambda=488 \mathrm{~nm}$; emission bandpass, 505-550 nm), AF568 was excited by helium/neon laser ( $\lambda=568 \mathrm{~nm}$; emission bandpass, $595 / 40$ $\mathrm{nm}$ ), and NeuroTrace Nissl stain was excited by helium/neon laser $(\lambda=633 \mathrm{~nm}$; emission long pass, $655 \mathrm{~nm}$; dichroic mirror, 405/488/561/633/KP725).

Imaging of putative synaptic contacts. First, an overview image was acquired to confirm the position of AF568-filled cells within MEC. An air PlanApo $10 \times, 0.45$ NA lens was used at the resolution of $1024 \times 1024$ pixels, 8-bit sampling, and $z$ increment of $10 \mu \mathrm{m}$. Next, the colocalization of AF568 and retrograde FB labeling was confirmed for each filled cell. For this, an air PlanApo $20 \times, 0.8$ NA objective lens was used at the resolution of $1024 \times 1024,8$-bit sampling, and $z$ increment of $5 \mu \mathrm{m}$. Finally, for high-resolution 3D analysis, a detailed scan of the AF488 (RSC fibers) and AF568 (MEC layer V cells) channels was taken using a $63 \times, 1.40$ NA oil DIC objective lens at a resolution of $1024 \times 1024$ pixels, 8 -bit sampling, and $z$ increment of $0.35 \mu \mathrm{m}$. The optical section thickness was set to $0.7 \mu \mathrm{m}$ by adjusting the pinhole for each channel. After 3D reconstruction and mapping (see below), each putative contact was then imaged in detail using $64 \times, 1.40$ NA oil DIC objective lens at a resolution of $256 \times 256$ pixels, zoom 6, 8-bit sampling, and $z$ increment of $0.35 \mu \mathrm{m}$.

Imaging of synaptic markers. In case of quadruple staining of synaptic contacts, the linear unmixing of closely located fluorescence peaks was performed using the Zeiss Meta unit and ZEN software. For three of the unmixed fluorochromes (AF488, AF514, and AF568), a reference emission spectrum was acquired using the argon laser excitation $\left(\lambda_{\text {excitation }}=\right.$ $514 \mathrm{~nm}$; dichroic mirror, NT 80/20; $\lambda_{\text {emission }}=497-583 \mathrm{~nm} ; \Delta \lambda=10$ $\mathrm{nm})$ at $64 \times, 1.40 \mathrm{NA}$ oil DIC objective lens at a resolution of $256 \times 256$ pixels, zoom 6, 8-bit sampling, and the $z$ increment of $0.35 \mu \mathrm{m}$. The spectral scan and unmixing of the specimen was then performed and followed by scanning of the AF633 channel with the same optical pathway $\left(\lambda_{\text {excitation }}=633 \mathrm{~nm}\right.$; dichroic mirror, NT 80/20; $\lambda_{\text {emission }}=$ $636-711 \mathrm{~nm})$. Final images were obtained by combining the results of the spectral scan (AF488, AF514 and AF568 channels) and the AF633 channel.

\section{Confocal image analysis}

$3 D$ reconstruction and mapping. Dendritic reconstruction was conducted as described previously (Kononenko and Witter, 2012). We used a custom plugin, "Skeleton tool" (Schmitt et al., 2004; Evers et al., 2005), for Amira version 4.1.2 to trace the dendritic trees and positions of the spines. For the Sholl analysis (Sholl, 1953), the number of branches crossing concentric spheres of increasing radius $(\Delta r=10 \mu \mathrm{m})$ originating at the soma was counted. Spine density was expressed as the number of spines per $10 \mu \mathrm{m}$ of dendrite length. To quantify the number of BDAfilled putative axonal boutons and their distribution along reconstructed dendrites, the dendritic surface was expressed as triangles (Evers et al., 2005). The BDA-positive pixels were identified by thresholding the AF488 channel according to the Otsu method (Otsu, 1979). The proximity of BDA-positive voxels within $300 \mathrm{~nm}$ from each surface element identified as a triangle was calculated and expressed as heat map on the dendritic surface. Finally, for each putative contact, the zoomed image was analyzed, and it was determined whether it adheres to previously established criteria of a presynaptic bouton (Wouterlood et al., 2008), being an axonal swelling having a diameter three times bigger than the preceding fiber.

Synaptic reconstruction. Resliced and quadruple-labeled images (presynaptic fibers, AF488; synaptophysin, AF514; postsynaptic dendrites, AF568; postsynaptic PSD-95, AF633) were loaded into FIJI software, and previously evaluated putative synaptic contacts were again identified using the AF488 and AF568 channels. The distribution of each fluorochrome along the axis connecting the center of a presynaptic bouton and the center of dendritic spine (for spine synapses) or dendritic segment (for shaft synapses) was measured. Putative contacts showing local labeling peaks for both synaptophysin (AF514) and PSD-95 (AF633) along that axis (between peaks for AF488 and AF568) were considered synaptic.
Because the axial resolution of optical microscopy is relatively poor, only the synapses in the $x-y$ plane were measured. $3 \mathrm{D}$ reconstructions of the synapses were performed in Amira version 4.1. The confocal stacks were filtered using the Gaussian filter and thresholded using Otsu's algorithm (Otsu, 1979), and surfaces for each channel were rendered and combined.

$m$ Cherry imaging and axonal tracing. First, an overview of biocytinfilled cells within layer $\mathrm{V}$ of MEC and trajectory of their axons was acquired using an air PlanApo 20×, 0.8 NA objective, resolution of $1024 \times$ 1024,8 -bit sampling, and $z$ increment of $2 \mu \mathrm{m}$. Then, a detailed scan of the AF488 (biocytin-filled cells), AF568 (AAV-expressing cells), and NeuroTrace Nissl stain was obtained $(40 \times, 1.30$ NA oil DIC objective lenses were used at resolution of $1024 \times 1024$ pixels, 8 -bit sampling, and $z$ increment of $0.5 \mu \mathrm{m}$ ). The $20 \times$ image stacks were then loaded into the Simple Neurite Tracker plugin in FIJI software, and axonal trajectories were plotted.

\section{Statistical analyses}

\section{All numbers are reported as mean \pm SEM.}

Electron microscopic experiments. The relative numbers of synapse types in each hemisphere and each animal were compared with a Fisher's exact test. Significant differences were accepted at $p<0.05$. Measured lengths of PSDs and the average of the longest and shortest diameter of the presynaptic boutons were imported into SPSS. ANOVA and post hoc analysis of least significant difference were used to assess different sources of variation of the morphological data. Significant differences were accepted at $p<0.05$.

Optogenetic experiments. Patched cells were grouped as interneurons or principal neurons based on electrophysiological and morphological characteristics. The average input resistances and kinetics of APs generated in response to depolarizing current step and onset were compared with two-sample $t$ tests. Differences in onset time after photostimulation of retrosplenial and entorhinal neurons were compared using twosample $t$ tests. Significant differences were accepted at $p<0.05$.

Confocal experiments. The proportionality between the density of labeled axons and the number of synaptic contacts assessed in the confocal microscope was assessed with $F$ test for linear regression. Whether the distribution of contact frequencies normalized to the plexus density was unimodal or polymodal were tested with a Kolmogorov-Smirnov test. Significant differences were accepted at $p<0.05$.

\section{Results}

\section{Morphological assessment of synaptic contacts in MEC}

In view of the known topographical organization of the RSC projection to MEC (Shibata, 1994; Jones and Witter, 2007), we aimed to inject BDA in multiple sites in caudal RSC to obtain a dense terminal plexus in MEC (Fig. 1A1,B1). Of the 11 animals used in the experiments destined for EM, seven animals had successful injections in RSC, without involvement of deep adjacent white matter. In total, we obtained 16 injections of BDA in RSC: seven in caudal A29ab, three in caudal A29c, two in intermediate rostrocaudal A29c, and four in caudal A30. All injections in caudal RSC resulted in a densely labeled terminal plexus in layer $V$ of dorsal and intermediate MEC and layer III and V of dorsal presubiculum. Sparse labeling was observed in layer III of MEC. These observations are in accordance with previously published data (Shibata, 1994; Jones and Witter, 2007; Kononenko and Witter, 2012). The labeled fibers in layer V were relatively thick and had clearly visible varicosities. We subsequently selected two animals that had the densest terminal labeling after processing the tissue for EM analysis and good preservation of the ultrastructure. In animal 12901, the injections were located in layers V and VI of caudal A29ab in the right hemisphere and in layers IV and V of caudal A29c in the left hemisphere. In animal 13976, the center of the injection in the left hemisphere was located in layer II-IV of caudal A30, whereas in the right hemisphere, it involved all layers of caudal A30. In the latter animal, BDA-filled neurons 
were observed in the distal part of the septal subiculum. This is likely a result of retrograde transport of BDA along subicular axons with terminals in the area in which the injections were placed (Vogt and Miller, 1983; Köhler, 1985; Witter et al., 1990; van Groen and Wyss, 1990, 2003; Miyashita and Rockland, 2007). It cannot be ruled out that BDA is transported anterogradely from the subiculum, labeling axon collaterals also terminating in the deep layers of MEC and thereby biasing the results. However, we find this very unlikely because the number of retrogradely filled neurons was very low, we never observed BDA-filled axons leaving the subiculum, and subicular neurons rarely have divergent extrinsic axon collaterals, implying that retrogradely labeled cells that project to RSC do not likely project to MEC as well (Naber and Witter, 1998).

\section{Quantification of synapses and postsynaptic targets}

In the ultrathin sections of MEC layer V, obtained from either of the two animals, labeled axons and axon terminals could easily be identified by the presence of clear DAB deposits. We observed both asymmetrical and symmetrical synapses. The first were characterized by having a thick PSD (more than twice the thickness of the PSD) and a wide synaptic cleft. Spherical vesicles could be observed in the presynaptic terminal (Figs. $2 A-D, 3 A$ ). Symmetrical synapses had a postsynaptic and presynaptic density of equal thickness, a narrow synaptic cleft, and pleomorphic presynaptic vesicles were less frequently encountered (Figs. 2E, 3B; Gray, 1959; Uchizono, 1965; Colonnier, 1968). For all synapses that lacked a clear asymmetrical morphology, we analyzed consecutive serial sections of entire presynaptic and postsynaptic complexes (Fig. 3).

Postsynaptic targets were either dendritic shafts characterized by microtubules or mitochondria in the cytoplasm, or dendritic spines characterized by their overall dimensions, the presence of clear cytoplasm, and/or the presence of a spine apparatus (Gray, 1959). No axo-axonic or axo-somatic synapses were observed. PSDs were commonly continuous (Figs. $2 A, B, D-F, 3$ ), although perforated synapses were observed as well (Figs. 2C, 4B). In general, presynaptic elements formed synapses with only one postsynaptic element, so-called single synaptic boutons (SSBs), although multiple synaptic boutons (MSBs) were regularly observed as well (Figs. 2D, 4).

In total, 262 boutons, forming 301 synapses on identified postsynaptic targets, were characterized in both hemispheres of two animals (Table 1). Analyses revealed no statistically significant differences in relative numbers between the two rats or their four hemispheres. In both animals, 98\% $(n=296)$ of the labeled terminals in layer $\mathrm{V}$ of MEC were characterized as part of asymmetrical synapses, whereas $2 \%(n=5)$ of the synapses were classified as symmetrical. Dendritic spines represented $91 \%(n=273)$ of the postsynaptic targets, whereas $9 \%(n=28)$ were dendritic shafts. In $36 \%(n=10)$ of the synapses onto dendritic shafts, these shafts showed additional multiple unlabeled synaptic contacts showing a circular arrangement around the shaft (Figs. 2F, 3A, 4A).

The majority of the asymmetrical synapses $(92 \%, n=271)$ contacted dendritic spines, whereas a small fraction $(8 \%$, $n=25)$ contacted shafts. In contrast, symmetrical synapses showed no clear preference for dendritic spines or shafts (two symmetrical synapses on dendritic spines and three on dendritic shafts). We observed that, of the asymmetrical synapses, $13 \%(n=34)$ were of the MSB type. These boutons made synapses with two to four postsynaptic elements. The MSBs contacted either only dendritic spines $(n=29$; Fig. $4 B$ ) or both dendritic spines and dendritic shafts $(n=5$; Fig. $4 A)$. Furthermore, $22 \%(n=59)$ of the asymmetrical synapses were of the perforated type, and they contacted dendritic spines $(n=56)$ or dendritic shafts $(n=3)$. 

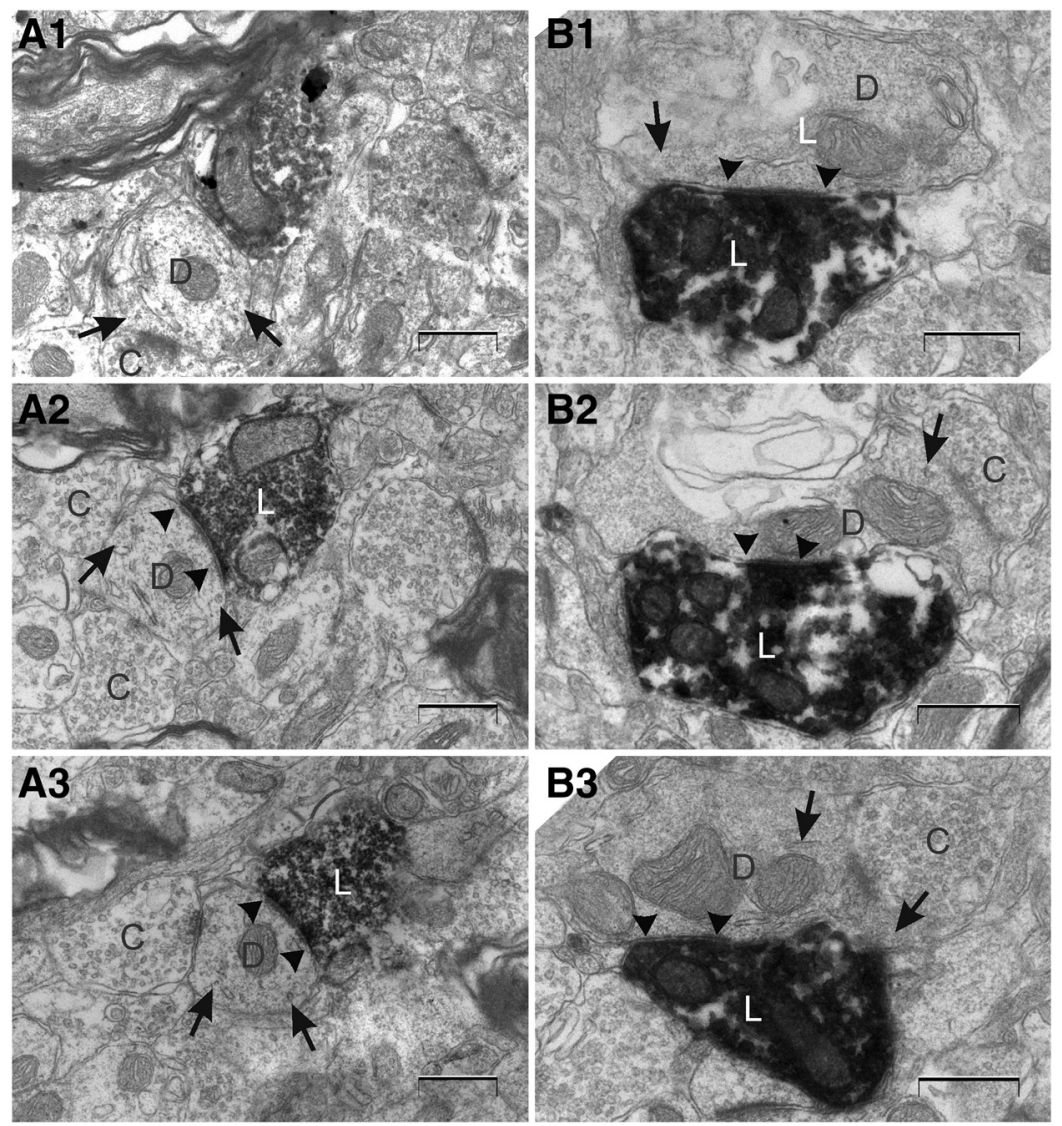

Figure 3. Representative electron micrographs taken from a series of ultrathin sections. Series of sections through an asymmetrical $(\boldsymbol{A 1} \mathbf{A} \mathbf{A})$ and a symmetrical synapse $(\boldsymbol{B} 1-\boldsymbol{B} 3)$ between a labeled axon terminal and a dendritic shaft in layer $V$ of MEC of animal 12901. The asymmetrical synapse (A1-A3) has a thick PSD (not developed in $\boldsymbol{A} 1$ and conspicuous in $\boldsymbol{A 2}$ ), round vesicles, and a wide synaptic cleft. The shaft is sectioned approximately perpendicular to its long axis. The symmetrical synapse (B1-B3) has a thin PSD (consistent throughout the series), pleomorphic vesicles, and a narrow synaptic cleft. The shaft is sectioned approximately parallel to its long axis. Converging inputs from unlabeled axon terminals to both shafts are evident. Synaptic specializations are indicated with arrowheads, and microtubuli are marked with arrows. L, Labeled axon terminal; D, dendrite; C, converging unlabeled axon terminal. Scale bars, $500 \mathrm{~nm}$.
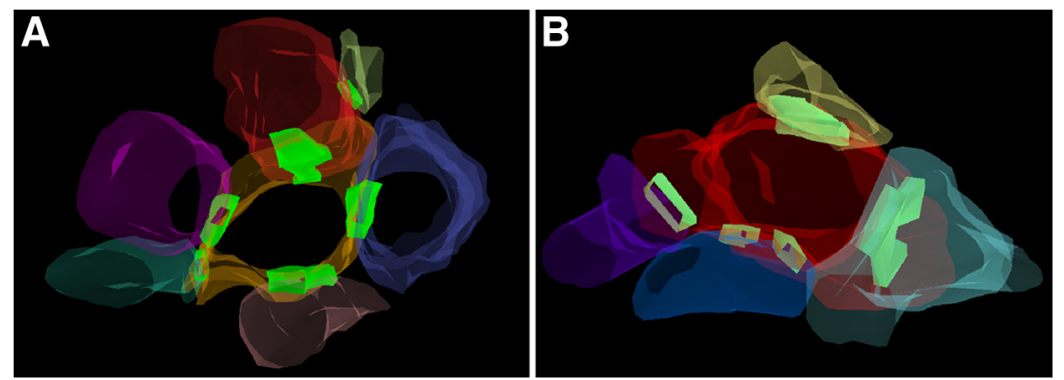

Figure 4. 3D reconstructions of representative synaptic complexes. $\boldsymbol{A}$, A labeled bouton (red), sampled from animal 12901, forming a synapse with a dendritic shaft (orange) and a dendritic spine (yellow). Four unlabeled boutons (blue, pink, turquoise, and purple) are making additional converging synaptic contacts with the same shaft. Synaptic clefts and specializations are color coded as light green. The reconstructions are based on serial sections of the synaptic complex demonstrated in Figure $2 F$. B, A labeled MSB (red), sampled from animal 13976, forming a synapse with four separate dendritic spines (yellow, turquoise, blue, and purple). The synapses made with the purple and blue spines are perforated. Synaptic clefts and specializations are color coded as light green.

The average diameter of all boutons was $860 \pm 17 \mathrm{~nm}$. Boutons with an asymmetrical synapse had an average diameter of $859 \pm 17 \mathrm{~nm}$, whereas boutons with a symmetrical synapse had an average diameter of $897 \pm 76 \mathrm{~nm}$. SSBs had an average diameter of $1025 \pm 49 \mathrm{~nm}$, whereas MSBs had an average diameter of $835 \pm 18 \mathrm{~nm}$. Boutons with nonperforated synapses had a signif- icantly smaller average diameter $(805 \pm$ $17 \mathrm{~nm}$ ) compared with boutons with a perforated synapse $(1050 \pm 39 \mathrm{~nm}$; $F_{(1,252)}=14.385, p<0.0005$; three-way ANOVA). The categorization of the synapse as symmetrical or asymmetrical or the categorization as MSB or SSB had no significant correlation with the average diameter $\left(F_{(3,252)}=0.755, p=0.52\right.$; $\left.F_{(1,252)}=0.407, p=0.52\right)$.

The average length of the PSDs was $352 \pm 8 \mathrm{~nm}$. Asymmetrical synapses on spines had an average PSD length of $347 \pm$ $8 \mathrm{~nm}$, asymmetrical synapses on shafts $402 \pm 33 \mathrm{~nm}$, and symmetrical synapses on spines $92 \pm 65 \mathrm{~nm}$, and symmetrical synapses on shafts had an average PSD length of $419 \pm 66 \mathrm{~nm}$. Synapses belonging to SSBs had an average length of $350 \pm 9$ $\mathrm{nm}$, whereas synapses belonging to MSBs had an average length of $357 \pm 17 \mathrm{~nm}$. Nonperforated synapses had a shorter average PSD length (317 $\pm 7 \mathrm{~nm})$ compared with perforated synapses $(495 \pm 18 \mathrm{~nm})$. Threeway ANOVA revealed that perforated synapses and synapse type had a significant correlation with the PSD length $\left(F_{(1,292)}=\right.$ 39.356, $p<0.0005 ; F_{(3,292)}=3.048, p=$ 0.029 ), whereas the classification as MSB or SSB was not significantly correlated with PSD length $\left(F_{(1,292)}=0.041, p=0.84\right)$. Post hoc analysis revealed that asymmetrical synapses on shafts had significantly larger PSD compared with asymmetrical synapses on spines $(p=0.027)$ and symmetrical synapses on shafts $(p=0.047)$.

\section{Functional assessment of synapses in MEC}

The morphological quantification of the majority of RSC synapses in MEC as asymmetrical onto spines indicated the presence of a direct, primarily excitatory input from RSC into spiny neurons in layer V of MEC (Gray, 1959; Eccles, 1964; Uchizono, 1965; Colonnier, 1968). To functionally validate this morphologically based inference, we applied an optogenetic in vitro approach (Petreanu et al., 2007). We expressed the ChR variant ChIEF in neurons of RSC by injecting rAAV vector expressing the fusion of ChIEF and the reporter protein mCherry under the $\alpha$ CaMKII promoter into caudal A29b and A29c (for details, see Materials and Methods). After 6 weeks, expression of mCherry was visible in all layers of RSC. Expression of the marker was only detected in the RSC cells and their projecting axons (Figs. 1A2,B2, 5); no ChIEF expression was observed in MEC neurons. Consistent with previous studies using anterograde tracers, strongly labeled projections from RSC to both deep and superficial layers of presubiculum, deep layers of parasubiculum, and deep layers of MEC were observed (Fig. 1B2). 
Table 1. Distribution of asymmetrical and symmetrical synapses and their postsynaptic targets

\begin{tabular}{|c|c|c|c|c|c|c|}
\hline \multirow[b]{2}{*}{ Animal } & \multirow[b]{2}{*}{ Boutons $(n)$} & \multirow[b]{2}{*}{ Synapses (n) } & \multicolumn{2}{|c|}{ Asymmetrical } & \multicolumn{2}{|c|}{ Symmetrical } \\
\hline & & & Spines & Shafts & Spines & Shafts \\
\hline $12901 \mathrm{R}$ & 95 & 104 & $85 \%$ & $13 \%$ & $0 \%$ & $2 \%$ \\
\hline $12901 \mathrm{~L}$ & 71 & 81 & $91 \%$ & $7 \%$ & $1 \%$ & $0 \%$ \\
\hline $13976 \mathrm{R}$ & 40 & 48 & $94 \%$ & $6 \%$ & $0 \%$ & $0 \%$ \\
\hline 13976L & 56 & 68 & $94 \%$ & $3 \%$ & $1 \%$ & $1 \%$ \\
\hline Total & 262 & 301 & $90 \%$ & $8 \%$ & $1 \%$ & $1 \%$ \\
\hline
\end{tabular}

Distribution of asymmetrical and symmetrical synapses and their postsynaptic targets in each of the two hemispheres of each of the two animals used for ultrastructural assessment. R, Right; L, left.

We first characterized the direct voltage responses of ChIEFpositive RSC cells to laser-scanning photostimulation. The stimulation grid $(8 \times 6,20 \mu \mathrm{m}$ spacing) was positioned over the recorded RSC layer $\mathrm{V}$ neurons (Fig. $5 A$ ). At high light intensity levels ( $>230 \mu \mathrm{W}$; Fig. $5 A$, black traces), illumination of each point on the grid evoked an AP in the recorded cell. In some cases, a brief burst of APs was recorded. With the decrease of laser power, stimulation at some grid points evoked subthreshold membrane depolarizations. At $23 \mu \mathrm{W}$ (Fig. 5A, red traces), only direct somatic stimulation evoked an AP. The average onset of the responses was $11.67 \pm 2.7 \mathrm{~ms}$ from the software trigger $(n=$ 288; Fig. 5C).

Previous studies showed that ChR-positive axons can survive in vitro after separating from the soma and that these axons respond to photostimulation with an AP and subsequent synaptic release (Petreanu et al., 2007). In $400-\mu \mathrm{m}$-thick horizontal slices of EC, we observed mCherry-labeled terminal fibers originating in RSC (Fig. 5B). In MEC, layer V neurons within the plexus were initially identified in the live IR-DIC image based on the appearance of their soma. The selected cells were patched, and main electrophysiological properties in response to $\pm 100 \mathrm{nA}$ current steps were determined (Fig. $5 B$ ). The vast majority of the cells ( $n=66,94 \%$ of total) were classified as layer V principal excitatory cells (Canto and Witter, 2012). Their average input resistance was $157 \pm 49 \mathrm{M} \Omega$, the average width at half peak of AP generated at threshold was $1.8 \pm 0.4 \mathrm{~ms}$, and their dendrites showed spiny morphology (Fig. 5B). Post hoc morphological analysis confirmed that these neurons were indeed pyramidal cells (Canto and Witter, 2012). In some instances $(n=5)$, the patched cells were identified as inhibitory layer $\mathrm{V}$ fast-spiking cells (FSCs). Their average input resistance was $132 \pm 40 \mathrm{M} \Omega$, which was not statistically different from the excitatory cells ( $p=$ 0.12). However, the AP generated in response to depolarizing current step had different kinetics from those seen in case of principal cells (average width at half peak was $0.6 \pm 0.1 \mathrm{~ms}, p<$ $0.001, t$ test). Moreover, the dendrites of these FSCs were spineless (Fig. 5D).

We performed recordings from putative postsynaptic layer $\mathrm{V}$ cells while photostimulating the presynaptic ChIEF-positive fibers. The stimulation grid was positioned above the basal dendrites of the recorded cells in layer V. The postsynaptic cells responded with EPSPs after stimulation in a subset of grid locations (Fig. $5 B, D, E$ ). The amplitude of the responses reached up to $10 \mathrm{mV}$ (with average response of $1.91 \pm 0.05 \mathrm{mV}$ ). The average onset time was $18.09 \pm 3.36 \mathrm{~ms}(n=732)$. The onset was significantly slower than in the case of direct optical stimulation of ChIEF-positive cells in RSC (Fig. $5 B ; p<0.001$ ), suggesting that the EPSPs in MEC were synaptic (Petreanu et al., 2007). To test whether the optically induced responses in MEC were mediated by presynaptic activation, we blocked the generation of APs by perfusing the slices with ACSF containing $5 \mu \mathrm{M}$ TTX. This treat- ment completely abolished responses in all recorded cells $(n=8$; Fig. 5E).

Principal cells of MEC layer V have been shown to display two main patterns of projection (Canto and Witter, 2012). Their axons can travel via the angular bundle, likely toward extrahippocampal targets, or they can project to superficial layers of MEC. We reconstructed and analyzed the axonal trajectories of 22 principal cells after the optogenetic experiments to determine which of the two types received the RSC input. We observed both axonal trajectories in the analyzed population. All reconstructed cells had axons projecting toward angular bundle. In a substantial fraction of neurons $(n=11)$, axonal collaterals were present in superficial layers (Fig. 6).

\section{Morphological analysis of putative synaptic contacts}

In the next series of experiments, we aimed to describe the target neurons of the RSC input to MEC layer V in more detail. Particularly, we wanted to identify cells in layer $\mathrm{V}$ that project to superficial layers II and III in MEC (Canto and Witter 2012) and to assess the overall distribution of RSC inputs onto the dendrites of these cells. In fixed slices containing anterogradely labeled RSC axons, we identified retrogradely labeled superficially projecting layer V neurons and filled them intracellularly with AF568 (Fig. $1 A 3, B 3)$. A total of 27 cells were successfully filled, and it was possible to reconstruct their basal dendritic tree for additional analysis. All reconstructed cells displayed dendritic morphology typical for layer V pyramidal cells (Hamam et al., 2000; Canto and Witter, 2012). Consistent with the earlier studies, the majority of the cells were multidirectional pyramidal cells $(n=22)$, although several horizontal cells were included $(n=5)$, characterized by having the majority of basal dendrites parallel and confined to the layer. The horizontal cells did not differ in any other aspect from the pyramidal cells, and both types were pooled together for additional analysis. A typical cell showed four to nine basal dendrites originating at the soma (Fig. 7A). Branching peaked at a distance of $60 \mu \mathrm{m}$ from the soma and continued up to $200 \mu \mathrm{m}$ (Fig. $7 B$ ). The basal dendritic tree extended up to $300 \mu \mathrm{m}$ in each direction. The proximal branches were almost devoid of spines, beyond $20 \mu \mathrm{m}$ (usually after first bifurcation). The spine density reached $\sim 10$ spines $/ 10 \mu \mathrm{m}$ and then peaked at 14 spines $/ 10 \mu \mathrm{m}$, $80 \mu \mathrm{m}$ from the soma (Fig. $7 C, D$ ). This spine density of reconstructed neurons was consistent with previous observations for layer V pyramidal neurons in MEC (Lingenhöhl and Finch, 1991).

After neuron reconstruction, the proximity of the BDApositive fibers labeled with AF488 was mapped onto the rendered dendritic surface (Fig. 7 E, F; Schmitt et al., 2004; Evers et al., 2005). Axons positioned within one voxel from the surface ( 300 $\mathrm{nm}$ in horizontal plane) were represented as a heat map according to their fluorescence intensity (Fig. $7 F, H$ ). Each individual putative contact between presynaptic and postsynaptic label was then verified for the presence of a presynaptic bouton. Axonal swellings were classified as boutons if the diameter of the swelling was at least three times bigger than the preceding fiber (Fig. 7I, J; Wouterlood et al., 2008). We verified whether the number of RSC synaptic contacts on each MEC layer $\mathrm{V}$ cell was proportional to the density of incoming fibers, as predicted by Peters' rule (Peters and Payne, 1993). Indeed, the density of labeled axons showed a linear correlation with the frequency of contacts for each cell $\left(R^{2}=0.74\right.$; Fig. $\left.7 G\right)$, and the distribution of contact frequencies normalized to the plexus density was unimodal ( $p=0.67)$. Of these putative presynaptic terminals, $84 \%$ (580 of 692) contacted spines, whereas the remaining 16\% (112 of 692) terminated on 

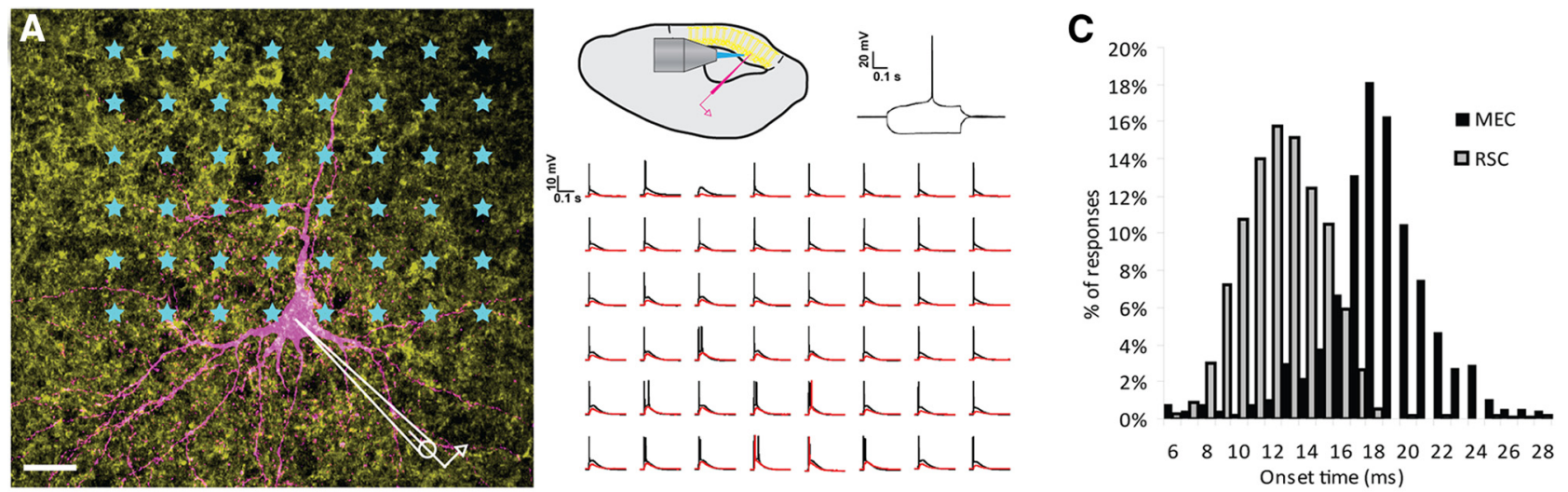

B

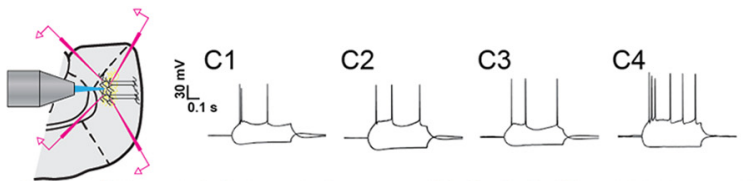

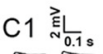
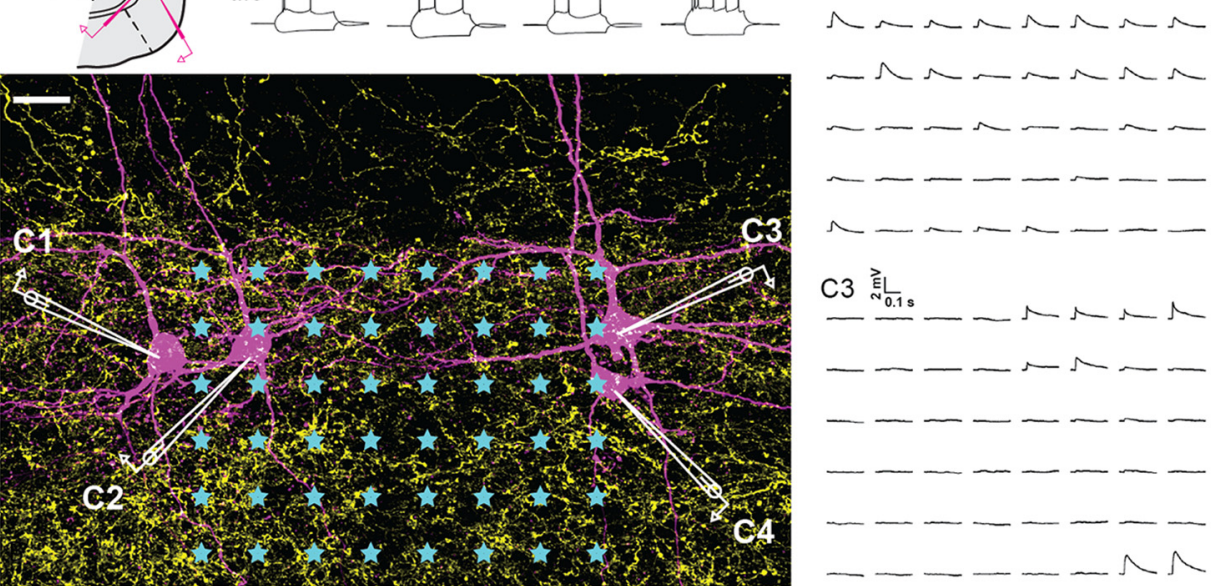

D
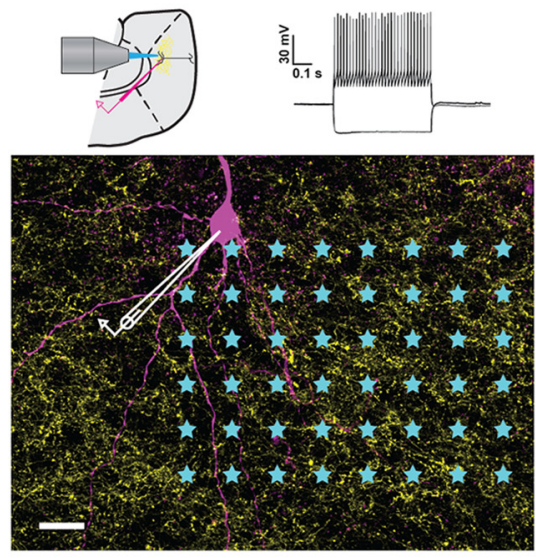

竞.

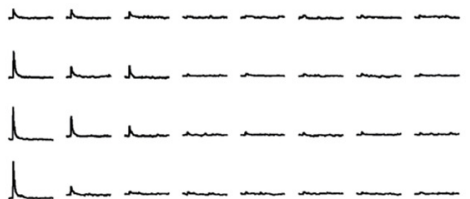

E

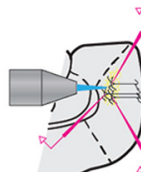

C1 真
窟 $\quad C 1$

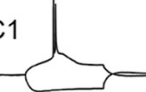

-TTX +TTX

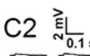

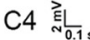

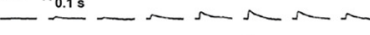

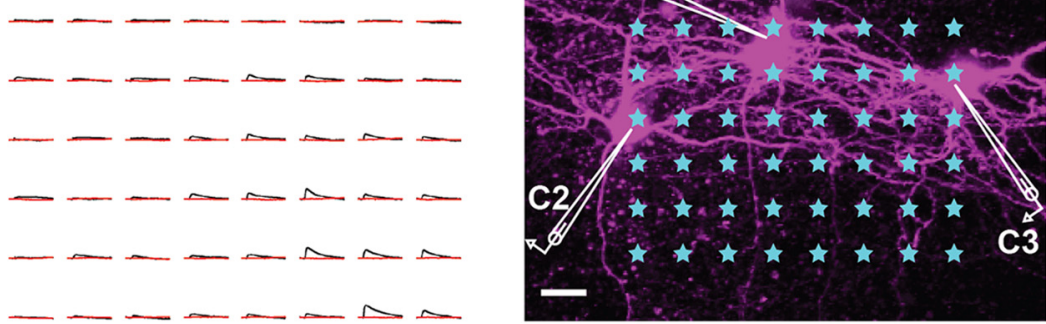

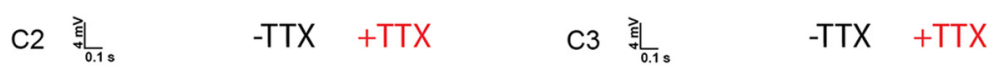

든..- - -

- - - - - -

$\Delta N \wedge \sim \sim N \sim \alpha$

$N \wedge N \wedge N \wedge N$

$\Lambda \wedge \wedge \wedge \wedge \wedge \wedge \wedge$

$\sim \sim-N \wedge \sim \sim \sim N$

$-\cdots N \Lambda N \Lambda N$

$\sim N N \Lambda N N$

$\sim \sim \wedge \wedge \wedge \wedge \wedge$

$-\ldots \wedge \wedge \wedge \Lambda$

Figure 5. Optogenetic activation of ChIEF-expressing RSC cells and their projection fibers in MEC. Laser stimulation of the grid pattern was applied as indicated by asterisks. Scale bars, $20 \mu \mathrm{m}$. Pulse duration was $2 \mathrm{~ms}$ with $250 \mathrm{~ms}$ intervals, delivered via a $40 \times$ water-immersion lens. Grid size was $8 \times 6$ with $20 \mu \mathrm{m}$ spacing between nodes. Order of activation (Figure legend continues.) 

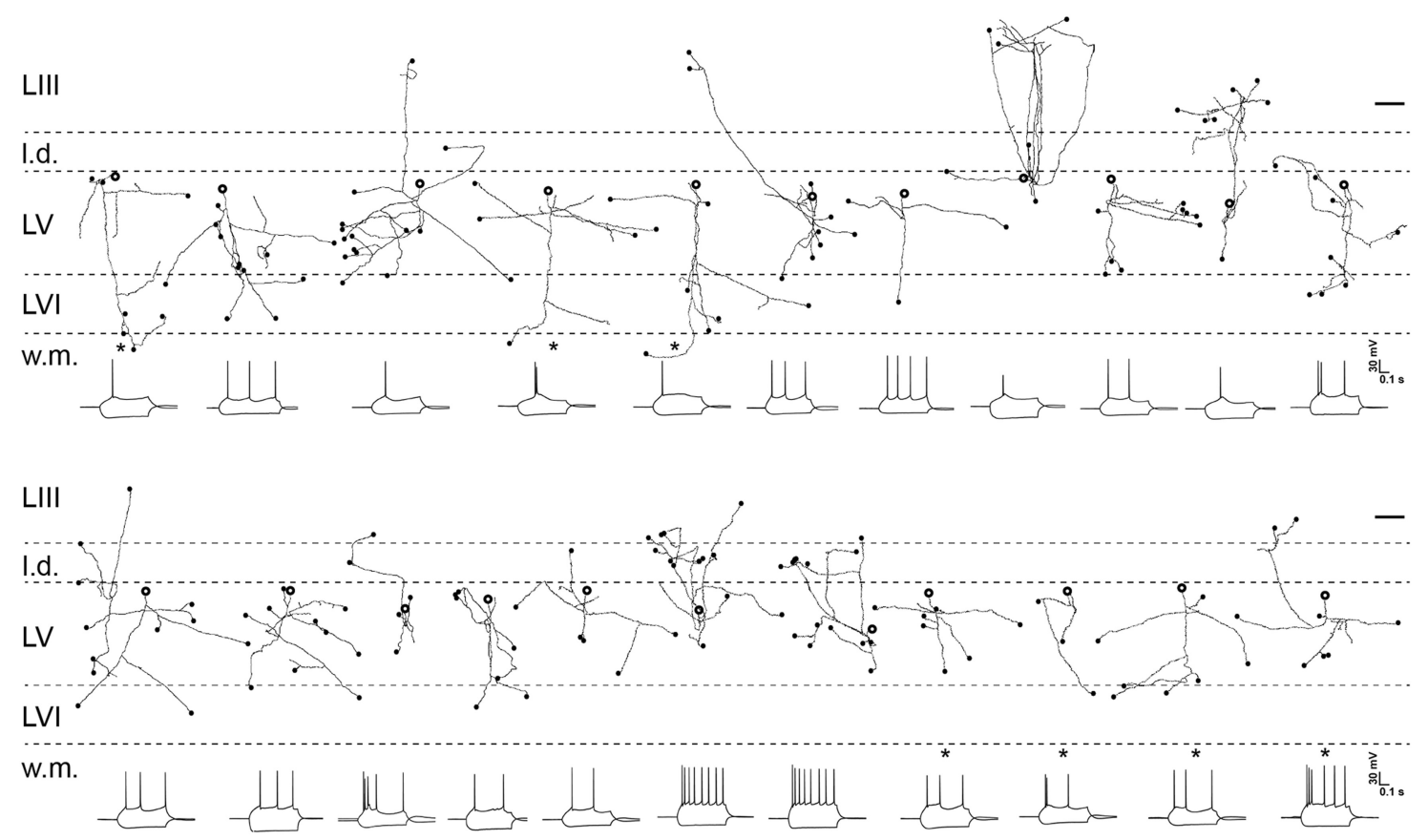

Figure 6. Individual axonal reconstructions of 22 pyramidal cells recorded in horizontal slices through MEC. The one interneuron (Fig. 5D) is not included. The position of the soma in layer $V$ is indicated with the bold open circle (size of the soma is not to scale). Axons that appeared to be cut at the surface of the slice are indicated by filled circles (scale bar, $200 \mu \mathrm{m}$ ). Below each neuron is the characteristic electrophysiological test response to current steps of $\pm 100 \mathrm{pA}$ (calibration: $0.1 \mathrm{~s}, 30 \mathrm{mV}$ ). The cells indicated with an asterisk are those for which the dendritic morphology is shown in Figure 5, B (4 cells in the bottom row) and $\boldsymbol{E}$ (3 cells in the top row). I.d., Lamina dissecans; L, layer; w.m., white matter.

shafts. The proximity of a presynaptic swelling and a dendritic shaft or spine does not automatically imply the presence of a synaptic contact (Peters and Palay, 1996; Wouterlood et al., 2003; Mishchenko et al., 2010). To substantiate our observations, we performed additional immunostaining of marker proteins for presynaptic terminals (synaptophysin) and for PSDs (PSD-95) and reconstructed 88 previously imaged putative contacts from

$\leftarrow$

(Figure legend continued.) was pseudorandom, and subsequent illumination of adjacent points of the grid was avoided. Pipettes positions are indicated in white. Yellow, mCherrypositive neurons and fibers; magenta, biocytin-filled cells. Each trace in $A, B, D$, and $\boldsymbol{E}$ represents response to stimulation at the corresponding point of the array. $A$, Direct response of a ChIEFexpressing cell in RSC to patterned laser stimulation. Laser power was first tuned to $230 \mu \mathrm{W}$ (black traces), and stimulation of each point evoked a single AP or a train of APs. Decrease in light intensity to $25 \mu \mathrm{W}$ resulted in elimination of AP events (red traces). Calibration: $0.1 \mathrm{~s}, 10$ $\mathrm{mV}$. Insets, Schematic diagram of recording configuration and test response of the RSC layer V cell to current steps of $\pm 100 \mathrm{pA}$. Calibration: $0.2 \mathrm{~s}, 20 \mathrm{mV}$. B , Somatic EPSP responses of MEC layer $V$ cells to patterned laser stimulation of RSC terminals expressing ChlEF. Each trace represents response to stimulation at the corresponding point of the array presented in $A$ for one of the four simultaneously recorded cells (C1-C4). Laser power at the specimen was $650 \mu \mathrm{W}$. Insets, Schematic diagram of recording configuration and test response to current steps of $\pm 100 \mathrm{pA}$ for cells C1-C4. C, Histogram showing the distribution of onset times for optically induced responses in RSC (gray bars) and MEC (black bars). Average onset time in RSC was $11.76 \pm 2.8 \mathrm{~ms}$, whereas in MEC it was significantly higher $(18.46 \pm 2.8 \mathrm{~ms}, t$ test,$p<0.001)$. $D$, FSC in MEC layer V showing EPSPs after stimulation of presynaptic RSC fibers. Calibration: $0.1 \mathrm{~s}, 2 \mathrm{mV}$. Insets, Schematic diagram of recording configuration and test response to current pulse of $\pm 100 \mathrm{pA}$. Calibration: $0.2 \mathrm{~s}, 30 \mathrm{mV}$. E, EPSPs evoked by RSC fiber stimulation in MEC layer V require presynaptic APs. Responses shown for three cells C1-C3. Insets, Schematic diagram of recording configuration and test response to current steps of $\pm 100 \mathrm{pA}$ for cells C1-C3. First, control responses were obtained by stimulating the presynaptic fibers with the grid pattern ( 30 repeats). Then the $\mathrm{Na}^{+}$channel blocker TTX $(5 \mu \mathrm{M})$ was infused for 2 min, and the grid stimulation was repeated in the presence of the toxin. Control traces (black lines) show typical responses. Blocking of $\mathrm{Na}^{+}$channels diminished the postsynaptic response to the level of baseline (red traces) in all observed cases. Calibration: $0.1 \mathrm{~s}, 4 \mathrm{mV}$. Inset, Configuration of a typical experiment and test response to current pulse of $\pm 100 \mathrm{pA}$. Calibration: $0.2 \mathrm{~s}, 30 \mathrm{mV}$. four neurons. Of these, 68 contacted spines and 20 contacted shafts. In $78 \%$ of the putative spine contacts $(n=53$ of 68$)$ and in $55 \%$ of the putative shaft contacts $(n=11$ of 20$)$, both presynaptic and postsynaptic markers were found, and these contacts could therefore be confirmed as synaptic (Fig. $7 \mathrm{~K}$ ). Extrapolating these percentages to the entire pool of putative synaptic contacts implies that $88 \%$ ( $n=452$ of 514$)$ of the axon terminals originating in RSC contacted spines, whereas $12 \%(n=62$ of 514) contacted shafts.

\section{Discussion}

Projections of the RSC to layer V of MEC are among the strongest cortical afferents to MEC (Burwell and Amaral, 1998). To study their potential impact on MEC, we used the anterograde transport of BDA and ChR-expressing rAAV to identify axons and terminals in layer V of MEC originating in RSC. Our findings that caudal RSC projects densely to layer $\mathrm{V}$, with very few fibers targeting layer III of MEC, are in line with previously reported observations (Shibata, 1994; Jones and Witter, 2007). The quantitative ultrastructural assessment of the morphology of the labeled presynaptic elements and their postsynaptic targets in layer $\mathrm{V}$ of MEC showed that the majority of the synapses is asymmetrical, indicating that these are excitatory. Less than $2 \%$ of the terminals are symmetrical, possibly representing a small inhibitory, likely GABAergic, projection (Gray, 1959; Eccles, 1964; Uchizono, 1965; Colonnier, 1968) that at least in part targets local inhibitory neurons (Caputi et al., 2013). This interpretation is strongly supported by our functional findings that laser stimulation of ChR-positive RSC axons in layer V of MEC exclusively resulted in excitatory responses in all postsynaptic cells studied. Therefore, we conclude that RSC provides a major excitatory drive to neurons in layer $\mathrm{V}$ and that inhibition plays only a minor role in this connection.

We further identified the layer V postsynaptic targets of RSC input. The electron microscopic data show a striking dominance of spines as targets for RSC inputs. Previous morphological stud- 

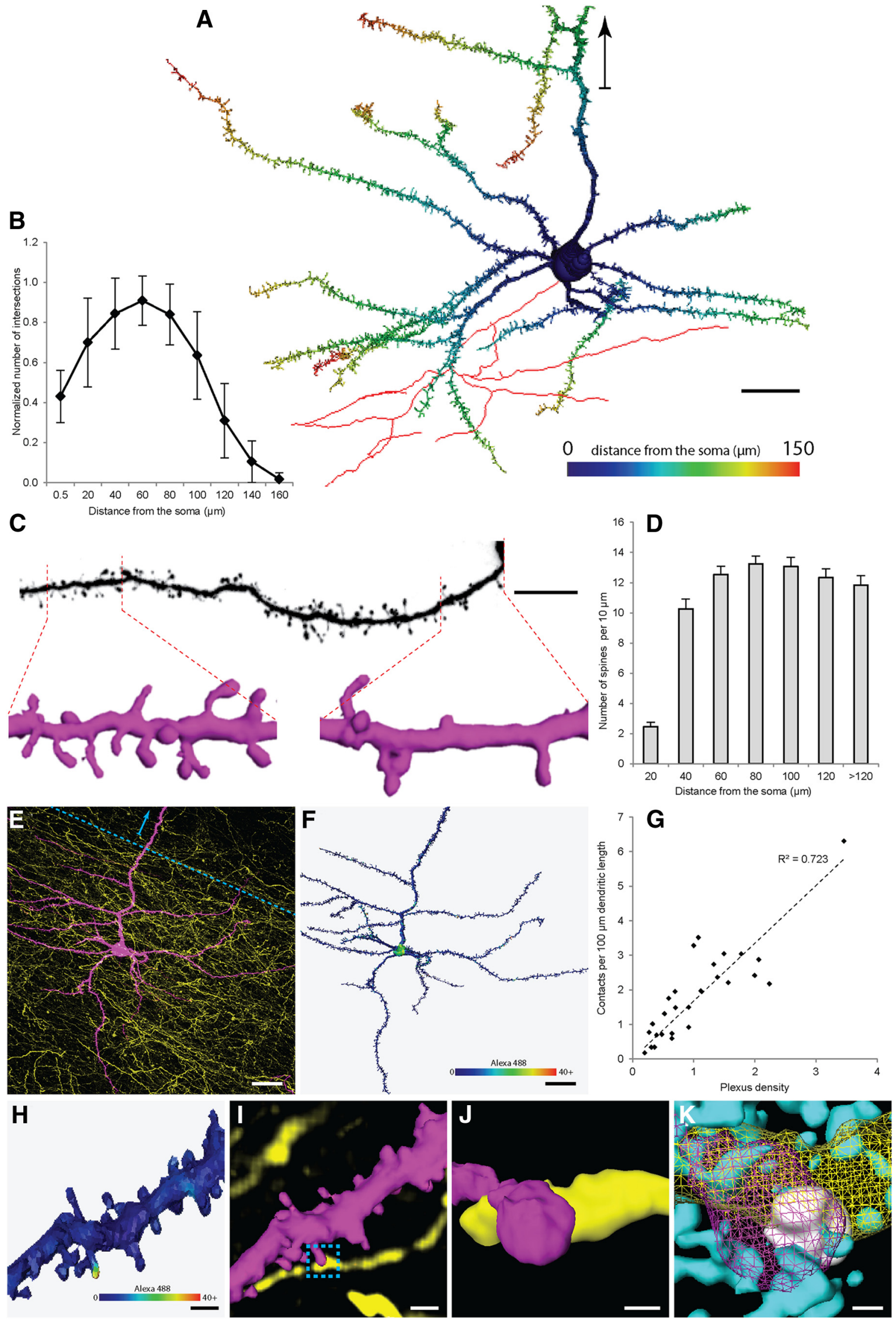

Figure 7. $\quad \boldsymbol{A}-\boldsymbol{D}$, Morphological properties of MEC layer V neurons that receive RSC input and project into layer I//III. $\boldsymbol{E}-\boldsymbol{K}$, Identification and quantification of putative RSC synaptic contacts on MEC layer V neurons. A, 2D projection of a typical reconstructed layer V cell showing the complexity of basal dendrites. Distance from the soma is color coded. Part of the axon reconstructed in red. Arrowhead points toward the pial surface. Scale bar, $20 \mu \mathrm{m}$. B, Sholl analysis showing changes in dendritic branching pattern of reconstructed layer $V$ neurons as a function (Figure legend continues.) 
ies have shown that principal neurons in MEC are commonly spiny (Wouterlood et al., 1995; Canto and Witter, 2012), and our observations thus indicate that principal neurons in layer $\mathrm{V}$ of MEC form a main target of RSC projections. Only a small percentage of the labeled axon terminals made synapses with smooth dendritic shafts, likely belonging to either interneurons (Wouterlood et al., 1995; Canto et al., 2008) or to spineless parts of dendrites of principal neurons as shown by our confocal results. The notion that the shafts at least in part represent interneuron dendrites is supported by the observations that a number of the postsynaptic shafts had multiple afferents from unlabeled axon terminals showing a circular arrangement. This phenomenon is commonly accepted to be a feature of interneurons (Kisvárday et al., 1985; Johnson and Burkhalter, 1996).

These morphologically based inferences are strongly supported by the optogenetic electrophysiological results that both spiny pyramidal neurons and smooth inhibitory FSCs in MEC layer $\mathrm{V}$ responded to optogenetic stimulation of RSC fibers with equal latencies. The existence of postsynaptic inhibitory neurons suggests the presence of an inhibitory feedforward loop within MEC layer V that would be triggered by RSC input. The presence of a disinhibitory projection, formed by GABAergic RSC neurons targeting MEC interneurons (Caputi et al., 2013), could not be confirmed with our optogenetic experiments, likely because of the limited sampling of interneurons.

Layer V principal cells project to a number of cortical and subcortical areas (Insausti et al., 1997), issue local axon collaterals confined to layer V (Hamam et al., 2000; Canto and Witter, 2012), and project intrinsically to superficial layers (Kloosterman et al., 2003b; van Haeften et al., 2003; Quilichini et al., 2010; Canto and Witter, 2012). Our data are in accordance with previously published accounts indicating that at least two populations exist: (1) one that projects both superficially and extrinsically; and (2) one that projects extrinsically with only local collaterals in layer V (Quilichini et al., 2010; Canto and Witter, 2012). Most importantly, our data lead us to conclude that both types of layer $\mathrm{V}$ pyramidal cells receive excitatory RSC input.

\footnotetext{
(Figure legend continued.) of distance from the soma ( $n=27$ from 8 animals). The Sholl values were normalized to the number of first-order dendrites to account for a different number of basal dendritic branches preserved during slice preparation. Sholl sphere diameter, $20 \mu \mathrm{m} . C$, Comparison of spine density between proximal $(0-20 \mu \mathrm{m}$ from the soma) and distal (100$120 \mu \mathrm{m}$ ) segment of basal dendrite. Scale bar, $30 \mu \mathrm{m}$. D. Histogram summarizing the changes in spine density of MEC layer V cells ( $n=27$ from 8 animals). Bin size, $20 \mu \mathrm{m}$. Error bars indicate SEM. E, Maximum projection of confocal image stack of BDA-labeled RSC fibers (AF488, yellow) and intracellularly filled postsynaptic cells in MEC layer V (AF568, magenta). Scale bar, $20 \mu \mathrm{m}$. Arrowhead points toward the pia surface. $F$, Surface rendering and RSC input mapping of cell imaged in $\boldsymbol{E}$. Staining intensity of BDA within $300 \mu \mathrm{m}$ of the reconstructed surface is mapped and color coded. Scale bar, $20 \mu \mathrm{m}$. G, Scatter plot showing the correlation between contact density and the number of RSC fibers present within the volume covered by dendritic tree (Peters' rule). The correlation was linear $\left(R^{2}=0.72\right)$, and the distribution of contact frequencies normalized to the plexus density was unimodal ( $p=0.67$, Kolmogorov-Smirnov test). For computation of the plexus density index, see Materials and Methods. $\boldsymbol{H}$, Surface rendering of a dendritic fragment with RSC input mapping. Staining intensity of BDA within $300 \mu \mathrm{m}$ of the reconstructed surface is mapped and color coded. Scale bar, $5 \mu \mathrm{m}$. I, Surface reconstruction of area shown in $\boldsymbol{H}$, overlaid with volume rendering of putative afferent RSC fibers (dendrite: AF568, magenta; axon: AF488, yellow). Dashed box shows the area magnified in J. Scale bar, 5 $\mu \mathrm{m}$. J, Surface reconstruction of synaptic contact targeted for immunostaining (marked by dashed box). Scale bar, $1 \mu \mathrm{m}$. $\boldsymbol{K}, 3 \mathrm{D}$ reconstruction of the synaptic contact shown in $\boldsymbol{H}-\boldsymbol{K}$. Slices containing AF568-filled cells and BDA-labeled RSC fibers were additionally immunostained with anti-synaptophysin and anti-PSD-95 antibodies. Bouton (yellow) and spine (magenta) reconstructed as mesh surface. Synaptophysin (white) and PSD-95 (cyan) reconstructed as solid surfaces.
}

We should point out that our experimental data only address the projection originating from a restricted, caudal part of the RSC, projecting preferentially to the dorsal half of MEC. In view of dorsoventral differences in grid-cell properties in MEC (Hafting et al., 2005; Stensola et al., 2012), it might be of interest to compare very dorsal with very ventral innervation patterns, but our current data do not allow to address this issue. However, based on the overall similar connectivity patterns for the projections from rostral and caudal RSC to MEC (Jones and Witter, 2007), and because we did not observe any striking differences between experimental data obtained within the dorsal half of MEC, we expect that our conclusions can be generalized to hold along the MEC dorsoventral axis.

\section{The role of RSC input in HF-MEC circuitry}

Principal neurons in layer V of MEC possess key anatomical and physiological features to serve an important role in integrating multiple external inputs (Canto et al., 2008). The dendritic trees of the principal cells in layer V span the total depths of MEC, receiving inputs that terminate in different layers. This has been shown for inputs to layers I-III (Medinilla et al., 2013), including those from the parasubiculum and presubiculum (Canto et al., 2012). Here we show that layer V principal neurons receive inputs from RSC. It is well established that layer V principal cells receive hippocampal output (van Haeften et al., 1995). Comparable with our results with respect to RSC input, among the hippocampal-receiving neurons are those that project superficially (Kloosterman et al., 2003b). Interestingly, the neurons that receive inputs from the parasubiculum and presubiculum also include those that send axon collaterals to superficial layers (Canto et al., 2012). These data thus indicate that layer $\mathrm{V}$ principal cells indeed integrate multiple inputs and subsequently forward this signal to superficial layers II and III.

The neuronal network of MEC has been implicated as a key component in brain systems mediating navigation (Moser and Moser, 2008). A striking cell type in superficial layer II of MEC is the grid cell (Hafting et al., 2005). Grid cells in MEC represent multiple positions in space, firing in a regularly patterned structure when the animal is moving in the environment. Moreover, grid cells universally code for all environments (Hafting et al., 2005). Directional information has been postulated as relevant for the emergence of stable grid-cell properties (Fuhs and Touretzky, 2006; McNaughton et al., 2006; Burgess et al., 2007) and for anchoring grid cells to distal cues (Knierim and Hamilton, 2011). This type of information is likely not generated within MEC but enters by way of the head-directional system. The headdirection signal originates in the recurrent network of the dorsal tegmental nucleus and the lateral mammillary nucleus and is relayed to multiple brain regions by way of the anterior dorsal nucleus of the thalamus (Taube, 2007). Although the presubiculum has been the main focus of research for head directionality, this type of information is also expressed in the firing patterns of neurons in RSC (Cho and Sharp, 2001). The relevance of RSC in spatial information processing is yet unclear, but it has been suggested that RSC integrates different spatial representations: (1) one based on path integration and (2) another based on external sensory information (Vann et al., 2009). We propose that the strong excitatory effect that RSC inputs exert on MEC layer V neurons is among the essential inputs for the parahippocampalhippocampal navigational system. This assumption is supported by findings that RSC lesions affect a wide range of tasks testing different navigational strategies (Vann et al., 2009). The most severe deficits were reported when the animal needed to change 
navigational strategies or integrate spatial information of different kinds (Vann et al., 2003; Pothuizen et al., 2008). Furthermore, during RSC inactivation, the firing of place cells in the hippocampus is less specific (Cooper and Mizumori, 2001). Because RSC does not project directly to the hippocampus, except for the subiculum (Sugar et al., 2011), we propose that this change in place-cell properties in addition to the behavioral deficits seen after RSC lesions reflect the disruption of RSC activity, indirectly influencing neurons in superficial layers of MEC, by way of the pathway shown in the present study.

\section{References}

Brun VH, Leutgeb S, Wu HQ, Schwarcz R, Witter MP, Moser EI, Moser MB (2008) Impaired spatial representation in CAl after lesion of direct input from entorhinal cortex. Neuron 57:290-302. CrossRef Medline

Burgess N, Barry C, O'Keefe J (2007) An oscillatory interference model of grid cell firing. Hippocampus 17:801-812. CrossRef Medline

Burwell RD, Amaral DG (1998) Cortical afferents of the perirhinal, postrhinal, and entorhinal cortices of the rat. J Comp Neurol 398:179-205. CrossRef Medline

Buzsáki G (1996) The hippocampo-neocortical dialogue. Cereb Cortex 6:81-92. CrossRef Medline

Canto CB, Witter MP (2012) Cellular properties of principal neurons in the rat entorhinal cortex. II. The medial entorhinal cortex. Hippocampus 22:1277-1299. CrossRef Medline

Canto CB, Wouterlood FG, Witter MP (2008) What does the anatomical organization of the entorhinal cortex tell us? Neural Plast 2008:381243. CrossRef Medline

Canto CB, Koganezawa N, Beed P, Moser EI, Witter MP (2012) All layers of medial entorhinal cortex receive presubicular and parasubicular inputs. J Neurosci 32:17620-17631. CrossRef Medline

Caputi A, Melzer S, Michael M, Monyer H (2013) The long and short of GABAergic neurons. Curr Opin Neurobiol 23:179-186. CrossRef Medline

Cho J, Sharp PE (2001) Head direction, place, and movement correlates for cells in the rat retrosplenial cortex. Behav Neurosci 115:3-25. CrossRef Medline

Chrobak JJ, Buzsáki G (1994) Selective activation of deep layer (V-VI) retrohippocampal cortical neurons during hippocampal sharp waves in the behaving rat. J Neurosci 14:6160-6170. Medline

Colonnier M (1968) Synaptic patterns on different cell types in the different laminae of the cat visual cortex. An electron microscope study. Brain Res 9:268-287. CrossRef Medline

Cooper BG, Mizumori SJ (2001) Temporary inactivation of the retrosplenial cortex causes a transient reorganization of spatial coding in the hippocampus. J Neurosci 21:3986-4001. Medline

Couey JJ, Witoelar A, Zhang SJ, Zheng K, Ye J, Dunn B, Czajkowski R, Moser MB, Moser EI, Roudi Y, Witter MP (2013) Recurrent inhibitory circuitry as a mechanism for grid formation. Nat Neurosci 16:318-324. CrossRef Medline

Eccles JC (1964) The physiology of synapses. Berlin: Springer Verlag.

Eichenbaum H, Lipton PA (2008) Towards a functional organization of the medial temporal lobe memory system: role of the parahippocampal and medial entorhinal cortical areas. Hippocampus 18:1314-1324. CrossRef Medline

Epstein RA, Parker WE, Feiler AM (2007) Where am I now? Distinct roles for parahippocampal and retrosplenial cortices in place recognition. J Neurosci 27:6141-6149. CrossRef Medline

Evers JF, Schmitt S, Sibila M, Duch C (2005) Progress in functional neuroanatomy: precise automatic geometric reconstruction of neuronal morphology from confocal image stacks. J Neurophysiol 93:2331-2342. Medline

Fuhs MC, Touretzky DS (2006) A spin glass model of path integration in rat medial entorhinal cortex. J Neurosci 26:4266-4276. CrossRef Medline

Gray EG (1959) Electron microscopy of synaptic contacts on dendrite spines of the cerebral cortex. Nature 183:1592-1593. CrossRef Medline

Gundersen HJ (1986) Stereology of arbitrary particles. A review of unbiased number and size estimators and the presentation of some new ones, in memory of William R. Thompson. J Microsc 143:3-45. CrossRef Medline

Hafting T, Fyhn M, Molden S, Moser MB, Moser EI (2005) Microstructure of a spatial map in the entorhinal cortex. Nature 436:801-806. CrossRef Medline

Hamam BN, Kennedy TE, Alonso A, Amaral DG (2000) Morphological and electrophysiological characteristics of layer $\mathrm{V}$ neurons of the rat medial entorhinal cortex. J Comp Neurol 418:457-472. CrossRef Medline

Insausti R, Herrero MT, Witter MP (1997) Entorhinal cortex of the rat: cytoarchitectonic subdivisions and the origin and distribution of cortical efferents. Hippocampus 7:146-183. CrossRef Medline

Ito HT, Schuman EM (2012) Functional division of hippocampal area CAl via modulatory gating of entorhinal cortical inputs. Hippocampus 22: 372-387. CrossRef Medline

Johnson RR, Burkhalter A (1996) Microcircuitry of forward and feedback connections within rat visual cortex. J Comp Neurol 368:383-398. CrossRef Medline

Jones BF, Witter MP (2007) Cingulate cortex projections to the parahippocampal region and hippocampal formation in the rat. Hippocampus 17:957-976. CrossRef Medline

Kisvárday ZF, Martin KA, Whitteridge D, Somogyi P (1985) Synaptic connections of intracellularly filled clutch cells: a type of small basket cell in the visual cortex of the cat. J Comp Neurol 241:111-137. CrossRef Medline

Kloosterman F, Van Haeften T, Lopes Silva FH (2000) Functional characterization of hippocampal output to the entorhinal cortex in the rat. Ann N Y Acad Sci 911:459-461. CrossRef Medline

Kloosterman F, Witter MP, Van Haeften T (2003a) Topographical and laminar organization of subicular projections to the parahippocampal region of the rat. J Comp Neurol 455:156-171. CrossRef Medline

Kloosterman F, Van Haeften T, Witter MP, Lopes Da Silva FH (2003b) Electrophysiological characterization of interlaminar entorhinal connections: an essential link for re-entrance in the hippocampal-entorhinal system. Eur J Neurosci 18:3037-3052. CrossRef Medline

Knierim JJ, Hamilton DA (2011) Framing spatial cognition: neural representations of proximal and distal frames of reference and their roles in navigation. Physiol Rev 91:1245-1279. CrossRef Medline

Köhler C (1985) Intrinsic projections of the retrohippocampal region in the rat brain. I. The subicular complex. J Comp Neurol 236:504-522. CrossRef Medline

Kononenko NL, Witter MP (2012) Presubiculum layer III conveys retrosplenial input to the medial entorhinal cortex. Hippocampus 22:881-895. CrossRef Medline

Lin JY, Lin MZ, Steinbach P, Tsien RY (2009) Characterization of engineered channelrhodopsin variants with improved properties and kinetics. Biophys J 96:1803-1814. CrossRef Medline

Lingenhöhl K, Finch DM (1991) Morphological characterization of rat entorhinal neurons in vivo: soma-dendritic structure and axonal domains. Exp Brain Res 84:57-74. Medline

Maguire EA (2001) The retrosplenial contribution to human navigation: a review of lesion and neuroimaging findings. Scand J Psychol 42:225-238. CrossRef Medline

McNaughton BL, Battaglia FP, Jensen O, Moser EI, Moser MB (2006) Path integration and the neural basis of the "cognitive map." Nat Rev Neurosci 7:663-678. CrossRef

Medinilla V, Johnson O, Gasparini S (2013) Features of proximal and distal excitatory synaptic inputs to layer $\mathrm{V}$ neurons of the rat medial entorhinal cortex. J Physiol 591:169-183. CrossRef Medline

Mishchenko Y, Hu T, Spacek J, Mendenhall J, Harris KM, Chklovskii DB (2010) Ultrastructural analysis of hippocampal neuropil from the connectomics perspective. Neuron 67:1009-1020. CrossRef Medline

Miyashita T, Rockland KS (2007) GABAergic projections from the hippocampus to the retrosplenial cortex in the rat. Eur J Neurosci 26:11931204. CrossRef Medline

Moser EI, Moser MB (2008) A metric for space. Hippocampus 18:11421156. CrossRef Medline

Naber PA, Witter MP (1998) Subicular efferents are organized mostly as parallel projections: a double-labeling, retrograde-tracing study in the rat. J Comp Neurol 393:284-297. CrossRef Medline

Narahashi T, Moore JW, Scott WR (1964) Tetrodotoxin blockage of sodium conductance increase in lobster giant axons. J Gen Physiol 47:965-974. CrossRef Medline

O'Keefe J, Dostrovsky J (1971) The hippocampus as a spatial map. Preliminary evidence from unit activity in the freely-moving rat. Brain Res 34: 171-175. CrossRef Medline 
O’Keefe J, Nadel L (1978) The hippocampus as a cognitive map. Oxford: Clarendon.

Otsu N (1979) Threshold selection method from gray-level histograms. IEEE Trans Syst Man Cybern 9:62-66. CrossRef

Paxinos G, Watson C (2007) The rat brain in stereotaxic coordinates, Ed 6. Amsterdam: Academic/Elsevier.

Peters A, Palay SL (1996) The morphology of synapses. J Neurocytol 25: 687-700. CrossRef Medline

Peters A, Payne BR (1993) Numerical relationships between geniculocortical afferents and pyramidal cell modules in cat primary visual cortex. Cereb Cortex 3:69-78. CrossRef Medline

Petreanu L, Huber D, Sobczyk A, Svoboda K (2007) Channelrhodopsin-2assisted circuit mapping of long-range callosal projections. Nat Neurosci 10:663-668. CrossRef Medline

Pothuizen HH, Aggleton JP, Vann SD (2008) Do rats with retrosplenial cortex lesions lack direction? Eur J Neurosci 28:2486-2498. CrossRef Medline

Quilichini P, Sirota A, Buzsáki G (2010) Intrinsic circuit organization and theta-gamma oscillation dynamics in the entorhinal cortex of the rat. J Neurosci 30:11128-11142. CrossRef Medline

Remondes M, Schuman EM (2004) Role for a cortical input to hippocampal area CA1 in the consolidation of a long-term memory. Nature 431:699703. CrossRef Medline

Sargolini F, Fyhn M, Hafting T, McNaughton BL, Witter MP, Moser MB, Moser EI (2006) Conjunctive representation of position, direction, and velocity in entorhinal cortex. Science 312:758-762. CrossRef Medline

Schmitt S, Evers JF, Duch C, Scholz M, Obermayer K (2004) New methods for the computer-assisted 3-D reconstruction of neurons from confocal image stacks. Neuroimage 23:1283-1298. CrossRef Medline

Shibata H (1994) Terminal distribution of projections from the retrosplenial area to the retrohippocampal region in the rat, as studied by anterograde transport of biotinylated dextran amine. Neurosci Res 20: 331-336. Medline

Sholl DA (1953) Dendritic organization in the neurons of the visual and motor cortices of the cat. J Anat 87:387-406. Medline

Solstad T, Boccara CN, Kropff E, Moser MB, Moser EI (2008) Representation of geometric borders in the entorhinal cortex. Science 322:18651868. CrossRef Medline

Spiers HJ, Maguire EA (2006) Thoughts, behaviour, and brain dynamics during navigation in the real world. Neuroimage 31:1826-1840. CrossRef Medline

Stensola H, Stensola T, Solstad T, Frøland K, Moser MB, Moser EI (2012) The entorhinal grid map is discretized. Nature 492:72-78. CrossRef Medline

Sugar J, Witter MP, van Strien NM, Cappaert NL (2011) The retrosplenial cortex: intrinsic connectivity and connections with the (para)hippocampal region in the rat. An interactive connectome. Front Neuroinform 5:7. CrossRef Medline

Taube JS (2007) The head direction signal: origins and sensory-motor integration. Annu Rev Neurosci 30:181-207. CrossRef Medline

Uchizono K (1965) Characteristics of excitatory and inhibitory synapses in the central nervous system of the cat. Nature 207:642-643. CrossRef Medline

Van Cauter T, Poucet B, Save E (2008) Unstable CA1 place cell representation in rats with entorhinal cortex lesions. Eur J Neurosci 27:1933-1946. CrossRef Medline

van Groen T, Wyss JM (1990) Connections of the retrosplenial granular a cortex in the rat. J Comp Neurol 300:593-606. CrossRef Medline

Van Groen T, Wyss JM (2003) Connections of the retrosplenial granular b cortex in the rat. J Comp Neurol 463:249-263. CrossRef Medline

van Haeften T, Jorritsma-Byham B, Witter MP (1995) Quantitative morphological analysis of subicular terminals in the rat entorhinal cortex. Hippocampus 5:452-459. CrossRef Medline

van Haeften T, Baks-te-Bulte LT, Goede PH, Wouterlood FG, Witter MP (2003) Morphological and numerical analysis of synaptic interactions between neurons in deep and superficial layers of the entorhinal cortex of the rat. Hippocampus 13:943-952. CrossRef Medline

van Strien NM, Cappaert NL, Witter MP (2009) The anatomy of memory: an interactive overview of the parahippocampal-hippocampal network. Nat Rev Neurosci 10:272-282. CrossRef Medline

Vann SD, Aggleton JP (2002) Extensive cytotoxic lesions of the rat retrosplenial cortex reveal consistent deficits on tasks that tax allocentric spatial memory. Behav Neurosci 116:85-94. CrossRef Medline

Vann SD, Kristina Wilton LA, Muir JL, Aggleton JP (2003) Testing the importance of the caudal retrosplenial cortex for spatial memory in rats. Behav Brain Res 140:107-118. CrossRef Medline

Vann SD, Aggleton JP, Maguire EA (2009) What does the retrosplenial cortex do? Nat Rev Neurosci 10:792-802. CrossRef Medline

Vogt BA, Miller MW (1983) Cortical connections between rat cingulate cortex and visual, motor, and postsubicular cortices. J Comp Neurol 216: 192-210. CrossRef Medline

Wesierska M, Adamska I, Malinowska M (2009) Retrosplenial cortex lesion affected segregation of spatial information in place avoidance task in the rat. Neurobiol Learn Mem 91:41-49. CrossRef Medline

Witter MP, Ostendorf RH, Groenewegen HJ (1990) Heterogeneity in the dorsal subiculum of the rat. Distinct neuronal zones project to different cortical and subcortical targets. Eur J Neurosci 2:718-725. CrossRef Medline

Wouterlood FG, Härtig W, Brückner G, Witter MP (1995) Parvalbuminimmunoreactive neurons in the entorhinal cortex of the rat: localization, morphology, connectivity and ultrastructure. J Neurocytol 24:135-153. CrossRef Medline

Wouterlood FG, Böckers T, Witter MP (2003) Synaptic contacts between identified neurons visualized in the confocal laser scanning microscope. Neuroanatomical tracing combined with immunofluorescence detection of post-synaptic density proteins and target neuron-markers. J Neurosci Methods 128:129-142. CrossRef Medline

Wouterlood FG, Boekel AJ, Kajiwara R, Beliën JA (2008) Counting contacts between neurons in 3D in confocal laser scanning images. J Neurosci Methods 171:296-308. CrossRef Medline

Zhang SJ, Ye J, Miao C, Tsao A, Cerniauskas I, Ledergerber D, Moser MB, Moser EI (2013) Optogenetic dissection of entorhinal-hippocampal functional connectivity. Science 340:1232627. CrossRef Medline 